\title{
Los objetivos de desarrollo sostenible: un principio de naturaleza incierta y varias dimensiones fragmentadas*
}

\author{
Sustainable development goals: an unpredictable \\ and fragmented principle
}

\begin{abstract}
Cástor Miguel díAZ BARRADO
Catedrático de Derecho Internacional Público y Relaciones Internacionales

Universidad Rey Juan Carlos de Madrid

castordiaz1@gmail.com
\end{abstract}

\begin{abstract}
Resumen: El desarrollo sostenible es una noción que surte efectos en el orden jurídico internacional. Es una noción evolutiva y acumulativa y sus efectos dependen de la aplicabilidad de ciertos principios esenciales del derecho Internacional. Los Objetivos de Desarrollo Sostenible (ODS), formulados en 2015, pueden contribuir a conformar el desarrollo sostenible como un principio «constitucional» y a facilitar que se deriven derechos y obligaciones de este principio. Los ODS refuerzan la noción de desarrollo sostenible. Las diversas dimensiones del desarrollo sostenible ayudan a configurar un principio estructural pero, al mismo tiempo, pueden debilitar el significado, contenido y alcance del principio. La comunidad internacional precisa de un principio esencial que reconozca el desarrollo sostenible y que imponga obligaciones a los Estados que entrañen, en su caso, responsabilidad internacional.
\end{abstract}

Palabras clave: Concepto de desarrollo sostenible. Objetivos de desarrollos sostenible. Dimensiones de los ODS. Derechos humanos y desarrollo sostenible. Comunidad internacional y desarrollo.

\begin{abstract}
Sustainable development is a notion which has an impact in the International Legal Order. In fact, it is an evolutive and cumulative concept. Its effects depend on how some structural principles of International Law are applied. Sustainable Development Goals (SDG), which were set down in 2015, offer an opportunity to regard the sustainable development as a «constitutional principle». As a consequence, rights and obligations could arise from this principle. The notion of sustainable development is reinforced thanks to SDG. Sustainable development various dimensions would indeed help to set it up as a fundamental principle, but, at the same time, however, they could weaken the meaning and scope of this principle. The International Community needs a principle by which the sustainable development is recognised and, at the same time, States obligations may be established, including, if necessary, international responsibility
\end{abstract}

Keywords: Sustainable Development concept. Sustainable Development Goals. SDGs dimensions. Human Rights and Sustainable Development. International Community and Development.

Sumario: INTRODUCCIÓN. I. ALGUNOS RETAZOS EN LA EVOLUCIÓN DEL DESARROLLO SOSTENIBLE. II. LA CONFIGURACIÓN DEL PRINCIPIO DE DESARROLLO SOSTENIBLE. a) Desarrollo y cooperación internacional. b) Desarrollo y protección internacional de los derechos humanos. c) La estrecha relación entre desarrollo y medioambiente. III. PRINCIPALES DIMENSIONES DEL DESARROLLO SOSTENIBLE. CONCLUSIONES.

* El presente trabajo forma parte del proyecto de la Cátedra sobre desarrollo y erradicación de la pobreza (SDG-FUND y URJC) V528; y del proyecto I+D titulado «Actores económicos internacionales y derechos humanos. Especial relevancia para España». DER2014-55484-P. Se realiza, también, en el marco de las Acciones de Dinamización, «Redes de Excelencia», del Plan Nacional de I+D+I «Nuevos Desafíos del Derecho Internacional» (Ref. DER2015-69273REDT), MINECO/FEDER, UE». 


\section{INTRODUCCIÓN}

L

a comunidad internacional ha decidido poner en marcha una obra de gran envergadura que asegure, por fin, el bienestar de la humanidad. Como se sabe, el 25 de septiembre de 2015, la Asamblea General de las Naciones Unidas adopta, mediante la Resolución 70/1, la Declaración: «Transformar nuestro Mundo: la Agenda 2030 para el Desarrollo Sostenible» que fija 17 objetivos y 169 metas. Esto supone «un plan de acción a favor de las personas, el planeta y la prosperidad, que también tiene la intención de fortalecer la paz universal y el acceso a la justicia ${ }^{1}$. Nada más cerca de la realidad y nada más lejos de lo inmediatamente posible. Los Objetivos del Desarrollo Sostenible (ODS) se perfilan, sin embargo, en un marco conceptual y normativo en el que se debe afirmar y conformar el principio del desarrollo sostenible. Su proclamación será, con toda seguridad, el último escalón en la evolución que viene experimentado, desde hace tiempo, este concepto ${ }^{2}$.

1 Preámbulo, <www.un.org/sustainabledevelopment/es/2015/09/la-asamblea-general-adopta-laagenda-2030-para-el-desarrollo-sostenible/>.

2 Algunos títulos de interés: Parris, Th. M. y Kates, R. W., «Characterizing and measuring sustainable development», Annual Review of Environment and Resources, vol. 28 (2003), pp. 559586; SACHS, J. D., «From Millennium Development Goals to Sustainable Development Goals», <www.thelancet.com>, vol. 379 (june, 2012); QUENTAL, N.; LOURENÇO, J. M. y NunES DA SILVA, F., «Sustainable development policy: goals, targets and political cycles», Sustainable Development, vol. 19, Issue 1 (January/February 2011), pp. 15-29; VoIGT, Ch., Sustainable Development as a Principle of International Law. Resolving Conflicts between Climate Measures and WTO Law, Leiden, 2009; SCHrIJVER, N., The Evolution of Sustainable Development in International Law: Inception, Meaning and Status, Leiden 2008 (The Evolution of Sustainable Development in International Law: Inception, Meaning and Status, RCADI, vol. 329 [2007], pp. 217-412); BARRAL, V., Le développement durable en droit international. Essai sur les incidences juridiques d'une norme évolutive, París, 2015; y «Sustainable Development in International Law: Nature and Operation of an Evolutive Legal Norm», EfIL, vol. 23, nº 2 (2012), pp. 377-400; Cordonier SEgGER, M. C.; GHering, M. W. y Newcombe, A., Sustainable Development in word investment international, Kluwer Law International, 2011; RODRIGO HERNÁNDEZ, A. J., El desafío del desarrollo sostenible: los principios de derecho internacional relativos al desarrollo sostenible, Fundación Privada Centro de Estudios Internacionales, Barcelona, 2015; Juste RUIZ, J., «El principio del desarrollo sostenible en el Derecho internacional y europeo del Ambiente: Algunas reflexiones conclusivas», Il principio dello sviluppo sostenibile nel Diritto internazionale ed Europeo dell'ambiente, Societá Italiana di Diritto Internazionali, XI Congreso, Alghuero 16-17 giugno 2006, 2007, pp. 333-356; MERCADO PACHECO, P., «Desarrollo sostenible y gobernanza: retóricas del derecho global y de la justicia ambiental», Derecho, globalización, riesgo y medio ambiente, Valencia, 2012; BERMEJO GARCÍA, R., «El derecho al desarrollo: un derecho complejo de contenido variable», ADI (1985), pp. 211243; MATSUI, Y., «The road to sutainable development: evolution of the concept of development in the UN», en GINTHER, K. y otros, Sustainable development and good governance, Dordrecht, 1995, pp. 53-71; y TLaDI, D., Sustainable development in International Law, Preotia, 2007. 
En la Agenda 2030 se establecen unas finalidades muy amplias y se presenta un entorno de actuación que debe condicionar el comportamiento de los Estados y demás actores de la sociedad internacional a lo largo del siglo XXI. Es una tarea ingente y en la que se suscitan, para el análisis, numerosos matices. La realidad del desarrollo va mucho más allá de los 17 ODS en sentido estricto, pero con estos Objetivos se trata, en el fondo, de alcanzar un escenario favorable para asegurar la igualdad y el bienestar de los seres humanos que habitan en el planeta. Por esto, 2015 se ha constituido como el momento preciso en el que se plantea una nueva agenda para la sociedad internacional del tiempo presente 3 .

Hace algún tiempo se dijo que «el logro de los ODM (era) un desafío, no sólo para los países en desarrollo, sino también para los países desarrollados y la comunidad internacional en general, ya que, por primera vez, se tomaron compromisos para proporcionar medios para apoyar su implementación y realización» ${ }^{4}$. Esto mismo se puede proclamar de los ODS. En verdad, la Agenda para el 2030 se presenta de una forma mucho más ambiciosa y se tienen en cuenta muchos más elementos del desarrollo sostenible. Sin duda, «los ODS recogen el testigo de los Objetivos de Desarrollo del Milenio (ODM) (...). A diferencia de los ODM, que abordaban problemas sociales, los ODS establecen metas en las tres dimensiones del desarrollo sostenible: social, económica y ambiental. Es más, los ODM iban dirigidos únicamente a los países en desarrollo, pero los ODS se aplicarán a todos los países» ${ }^{5}$.

La compleja formulación de los ODS no debe impedir que se aprecie su verdadero valor más allá de la consecución de las metas que se han marcado.

3 Se ha dicho que «este año representa un momento histórico a nivel mundial. Estamos siendo testigos de la construcción de una nueva agenda de desarrollo que definirá qué objetivos debe alcanzar la humanidad no sólo para satisfacer sus necesidades básicas, sino también para garantizar una vida digna a las generaciones presentes y futuras. Ante problemáticas tan devastadoras como la extrema pobreza, la enorme desigualdad entre las personas, la inequidad entre géneros y una creciente degradación ambiental, los países decidieron este año adoptar un nuevo marco de trabajo para los próximos 15 años que reemplazará los Objetivos del Milenio», $A B C$ de los objetivos de desarrollo sostenible: la importancia de la dimensión ambiental en la nueva agenda mundial de desarrollo, Colombia, 2015, p. 3.

4 Banco Interamericano de Desarrollo. Los Objetivos de Desarrollo del Milenio en América Latina y el Caribe: retos, acciones y compromisos, Washington, D.C., 2004, p. 8. Vid., también, SanaHuJA, J. A., «De los Objetivos del Milenio al desarrollo sostenible: Naciones Unidas y las metas globales post-2015», en Mesa, M., Focos de tensión, cambio geopolítico y agenda global, Anuario 2014-2015, Fundación Cultura de Paz, 2015, pp. 49-83.

5 Objetivos de desarrollo sostenible, Guía de implementación nacional para OSC dedicadas a SDSR, London, 2015, p. 2. 
Cada uno de los ODS resume el estado de la cuestión en la materia pero el conjunto de ellos expresa el significado que el desarrollo sostenible debe tener en el orden internacional. Por esto, los ODS suponen una sobresaliente aportación al concepto de desarrollo sostenible y, sobre todo, prestan una visión de la realidad internacional que debe traducirse necesariamente en términos políticos y jurídicos. Los ODS son, por ello, un paso más en el camino que conduce a la afirmación del desarrollo sostenible como principio no sólo político sino, también, con efectos jurídicos. En realidad, «the September 2015 Summit to adopt the post-2015 development agenda agreed a significant expansion in the number of goals and targets by comparison with the MDG framework. This was with a view to ensuring that the agenda was transformative. In turn, this reflected a majority belief that an integrated and multi-dimensional approach would prove a more fruitful way forward $»^{6}$. Lo que no sabemos es si la proclamación de los ODS será suficiente para que el desarrollo sostenible se convierta, por fin, en un principio estructural del orden internacional.

La expresión «desarrollo sostenible» forma parte de la terminología habitual de las relaciones internacionales pero todavía falta que llegue a alcanzar el estadio en el que produzca todos sus efectos prácticos. La consecución de algunos de los ODM ha contribuido, sin duda, a que se vaya confirmando una visión positiva del desarrollo sostenible. La mera formulación y el logro paulatino de los ODS constituirán los fundamentos de un nuevo principio en el orden internacional. La cuestión central a resolver es si los pasos dados por la comunidad internacional en los últimos años han logrado que el desarrollo sostenible se convierta plenamente en un principio estructural y, por ende, si las dimensiones de este desarrollo, que han recogido los diferentes instrumentos internacionales, expresan completamente los efectos que derivan de una noción de este tipo. La proclamación de los ODS y la implementación de la Agenda 2030 deberían ser suficientes para que se asista a la confirmación del desarrollo sostenible, en sus diversas dimensiones, como un principio esencial del ordenamiento jurídico internacional ${ }^{7}$.

No es fácil definir la noción de desarrollo sostenible pero, como lo indicó R. Bermejo García, «el desarrollo es un objetivo demasiado importante como

6 Lunn, J.; Downing, E. y Booth, L., «The Sustainable Development Goals and the post-2015 development agenda», Briefing Paper, n. 7291 (28 September 2015), p. 23.

7 Como lo ha indicado Rodrigo, A. J., «El objetivo hoy consiste en mejorar la implementación del desarrollo sostenible por medio del Derecho internacional», El desafío del desarrollo sostenible, cit., p. 175 . 
para dejarlo al libre arbitrio de cada uno y constituye un desafío para la Comunidad internacional desde que la Carta de las Naciones Unidas hiciera del mismo un fenómeno internacional por excelencia. Así, pues, el concepto de desarrollo merece, si no una definición, al menos sí una descripción ${ }^{8}$.

\section{Algunos Retazos EN la EVOluCión DEL DESARROLlo SOSTENIBLE}

La definición y alcance de los ODS es el resultado de una evolución constante. Han tenido lugar muchos momentos relevantes para las relaciones económicas internacionales y para el logro del desarrollo. Por eso, definir el desarrollo sostenible como un principio estructural del orden internacional e identificar las principales dimensiones que perfilan el principio que sustenta a los ODS implica no prescindir, en modo alguno, del análisis del proceso evolutivo y de cada uno de los aportes que se han ido produciendo en cada momento9. Los diversos instrumentos que se han pronunciado sobre este fenómeno han ido profundizando en la definición del concepto y en los perfiles que le otorgan un significado singular. El contenido y alcance del desarrollo sostenible y de las eventuales obligaciones que deriven sólo es posible determinarlos con base en los antecedentes que han ido dando forma a la noción. Como indica la Resolución 70/1, hay que destacar «los resultados de todas las grandes conferencias y cumbres de las Naciones Unidas, que han establecido una base sólida para el desarrollo sostenible y han ayudado a conformar la nueva Agenda $\gg^{10}$.

La noción de desarrollo y, por lo tanto, el significado de desarrollo sostenible encuentran sus fundamentos en la segunda mitad del siglo Xx. Más allá de las primeras aproximaciones, en los años sesenta y setenta de ese siglo, como la Conferencia de las Naciones Unidas sobre Medio Ambiente Humano, que tuvo lugar en Estocolmo del 5 al 16 de junio de 1972, hay que recordar la relevancia de las Conferencias internacionales que tuvieron lugar en el decenio de los

8 Bermejo García, R., «El derecho al desarrollo...», cit., p. 219. Un trabajo reciente y de mucho interés Faraminan GilberT, J. M., «Avances hacia una conceptualización del desarrollo sostenible», en VI Ecuentro Luso-español de Profesores de Derecho Internacional y Relaciones internacionales, «Desarrollo sostenible y Derecho Internacional», Valencia 24-25 de junio de 2016.

9 Vid., LunN, J.; Downing, E. y BoоTH, L., «The Sustainable Development Goals...», cit., pp. 6 ss.

10 A/Res/70/1, 21 de octubre de 2015, párr. 11; y RodrigO, A. J., El desafío del desarrollo sostenible, cit., pp. 22-43. 
noventa. En particular, conviene no olvidar las importantes aportaciones que se realizan en la Primera Conferencia de las Naciones Unidas sobre el Medio Ambiente y el Desarrollo que tuvo lugar en Río de Janeiro en $1992^{11}$. Pero será la Declaración del Milenio, adoptada el 8 de septiembre de 2000, en el marco de las Naciones Unidas, la que, de manera concreta, determine ocho Objetivos de Desarrollo del Milenio (ODM) y ponga el acento, definitivamente, en el carácter sustancial del concepto de desarrollo sostenible. Con ello, se señalan los componentes esenciales del desarrollo en la sociedad internacional y se nos dan las claves para comprender, con toda intensidad, el significado y alcance de esta realidad.

A partir de ahí se deja claro, al menos, que «los Objetivos declaran (...) una doble intencionalidad: de un lado, la voluntad de avanzar en una acción más concertada a favor del desarrollo y del bienestar mundial, coordinando las actuaciones de cada país y las de los Organismos internacionales en tareas que muestren su compromiso con los sectores más pobres de la Tierra, en diálogo con la ciudadanía; de otro, dotando a estas entidades y, en general, a las personas interesadas, de criterios, procedimientos e indicadores con los que evaluar las políticas que se adopten en cada contexto» ${ }^{12}$. Los ODM han sido útiles para conformar el marco de cooperación que conduzca al logro del desarrollo en la sociedad internacional. Con independencia de los resultados que finalmente se alcanzaron, en la Cumbre del Milenio se sentaron las bases para que el conjunto de los actores que intervienen en la sociedad internacional pudieran ir incorporando estos objetivos en las preocupaciones políticas y que se plasmaran en el plano normativo ${ }^{13}$.

Se había producido el cambio y sólo era necesario ir dotando de contenido conceptual y enriqueciendo los fundamentos y dimensiones que se señalan

11 Además, «la Cumbre Mundial sobre el Desarrollo Sostenible, la Cumbre Mundial sobre Desarrollo Social, el Programa de Acción de la Conferencia Internacional sobre la Población y el Desarrollo, la Plataforma de Acción de Beijing y la Conferencia de las Naciones Unidas sobre el Desarrollo Sostenible. Reafirmamos también las actividades de seguimiento de esas conferencias, incluidos los resultados de la Cuarta Conferencia de las Naciones Unidas sobre los Países Menos Adelantados, la Tercera Conferencia Internacional sobre los Pequeños Estados Insulares en Desarrollo, la Segunda Conferencia de las Naciones Unidas sobre los Países en Desarrollo Sin Litoral y la Tercera Conferencia Mundial de las Naciones Unidas sobre la Reducción del Riesgo de Desastres», A/Res/70/1, 21 de octubre de 2015, párr. 11.

12 Caride Gómez, J. A., «Nuevas perspectivas para un futuro viable: los Objetivos de Desarrollo del Milenio», Revista de Educación, número extraordinario (2009) (ejemplar dedicado a: Educar para el desarrollo sostenible), pp. 77-78.

13 Naciones Unidas, Objetivos de Desarrollo del Milenio, Informe de 2015, Nueva York, 2015. También, CARIDE GÓMEZ, J. A., «Nuevas perspectivas para un futuro viable...», cit. 
en la Declaración del Milenio. Como lo dicen J. A. Sanahuja y S. Tezanos «con el tránsito al siglo XXI se conformó una agenda mundial de desarrollo que situó a la lucha contra la pobreza humana -entendida desde una perspectiva multidimensional- como bandera de la acción solidaria internacional. Hasta entonces el sistema de cooperación para el desarrollo había respondido a una desigual y desequilibrada combinación de marcos internacionales, generalmente débiles, y a los intereses particulares de los donantes» ${ }^{14}$. La noción de desarrollo comenzaba a configurarse, en términos reales, como un valor propio de la comunidad internacional lo que facilitaba su comprensión como principio y ámbito de actuación en las relaciones internacionales. Muchas veces, sin embargo, los Objetivos de Desarrollo, en sentido amplio, son contemplados como meras metas a satisfacer sin que cuenten con un marco conceptual ni se fundamenten en valores singulares de la comunidad internacional ${ }^{15}$.

La adopción de la Declaración del Milenio representó, a mi juicio, una sabia combinación entre la necesidad de alcanzar metas concretas y objetivos precisos y la voluntad de dotar a la noción de desarrollo de los elementos que le permitan afirmase como principio fundamental del orden internacional. En realidad, «les OMD ont réussi à attirer l'attention du monde sur l'élimination de l'extrême pauvreté sous toutes ses formes et la réduction des inégalités entre les sexes. Ils ont accéléré les progrès vers ces objectifs et sont devenus un cadre normatif pour le développement ${ }^{16}$. Se inicia, entonces, el camino que progresivamente conducirá a la consideración de la noción de desarrollo como un principio más allá de que sea un concepto útil y necesario para comprender las relaciones internacionales contemporáneas.

La Conferencia de Naciones Unidas sobre Desarrollo Sostenible, celebrada en Río de Faneiro en $2012^{17}$ marca los componentes que conforman, definitivamente,

14 Sanahuja, J. A. y Tezanos, S., «Del milenio a la sostenibilidad: en ruta hacia la Agenda 2030 de Desarrollo Sostenible», Revista Temas, 254-255, Nueva agenda global de desarrollo, p. 16.

15 Para A. J. Rodrigo, se configura como un objetivo político, El desafío de desarrollo sostenible, cit., pp. 63 ss. Lo que está claro es que el desarrollo sostenible se concibe, en la actualidad, como uno de los principales propósitos de las Naciones Unidas, RoDRIGO, A. J., «El desarrollo sostenible como uno de los propósitos de las Naciones Unidas», en Pons, X., Las Naciones Unidas desde España. 70 Aniversario de las Naciones Unidas. 60 Aniversario del ingreso de España en las Naciones Unidas, Barcelona, 2015, pp. 265-291.

16 Lan, X.; Sachs, J. D.; Schmidt-Traub, G. y Tubiana, L., Définir des objectifs de développement durable à l'horizon 2030, Janvier 2013.

17 Sin olvidar la Cumbre Mundial sobre el Desarrollo Sostenible, en Johannesburgo, Sudáfrica, 2002. En esta Cumbre se asume «la responsabilidad colectiva de promover y fortalecer, en los planos local, nacional, regional y mundial, el desarrollo económico, desarrollo social y la pro- 
esta noción en el orden internacional. Esta Conferencia incorpora los aspectos que permiten definir el desarrollo sostenible en sus elementos esenciales y, más allá, dibuja con precisión las dimensiones de las que goza y sus efectos en el orden internacional. En el punto 4 de la Declaración Final se sostiene, con razón, que «la erradicación de la pobreza, la modificación de las modalidades insostenibles y la promoción de modalidades sostenibles de producción y consumo, y la protección y ordenación de la base de recursos naturales del desarrollo económico y social son objetivos generales y requisitos indispensables del desarrollo sostenible. (...) es necesario lograr el desarrollo sostenible promoviendo un crecimiento sostenido, inclusivo y equitativo, creando mayores oportunidades para todos, reduciendo las desigualdades, mejorando los niveles de vida básicos, fomentando el desarrollo social equitativo y la inclusión, y promoviendo una ordenación integrada y sostenible de los recursos naturales y los ecosistemas que preste apoyo, entre otras cosas, al desarrollo económico, social y humano, y facilite al mismo tiempo la conservación, la regeneración, el restablecimiento y la resiliencia de los ecosistemas frente a los problemas nuevos y emergentes». Además, se pone el énfasis, con nitidez, en cada una de las dimensiones que el desarrollo ha de tener si se quiere que sea viable. En efecto, «es necesario incorporar aún más el desarrollo sostenible en todos los niveles, integrando sus aspectos económicos, sociales y ambientales y reconociendo los vínculos que existen entre ellos, con el fin de lograr el desarrollo sostenible en todas sus dimensiones» ${ }^{18}$.

La formulación, en septiembre de 2015, de los ODS es, por lo tanto, el resultado de un proceso histórico en el que no sólo se indican metas concretas que se deben alcanzar y se van incorporando nuevos objetivos y metas sino que, también, se van sumando las perspectivas que definen la noción de desarrollo sostenible. Esta noción se va enriqueciendo, adquiriendo nuevas visiones y fortaleciendo las existentes. Pero, también, se va consolidando su carácter de valor fundamental de la sociedad internacional y, quizá, se abre camino definitivamente como principio esencial del orden internacional ${ }^{19}$. Se ha dicho

tección ambiental, pilares interdependientes y sinérgicos del desarrollo sostenible», párr. 5. En particular, ser reconoce que «la erradicación de la pobreza, la modificación de pautas insostenibles de producción y consumo y la protección y ordenación de la base de recursos naturales para el desarrollo social y económico son objetivos primordiales y requisitos fundamentales de un desarrollo sostenible», párr., 11.

18 A/CONF.216/L.1, 19 de junio de 2012, párrs. 3 y 4.

19 Lo que queda claro es «su carácter evolutivo que ha permitido incorporar nuevas aspiraciones, metas o problemas», Rodrigo, A. J., El desafío del desarrollo sostenible, cit., p. 59. 
que «es necesario que la Agenda Post-2015 esté basada en principios y valores compartidos. No hace falta inventárselos o acordarlos a través de procesos tediosos de negociación. En los tratados internacionales, las declaraciones y resoluciones políticas, sobre todo la Declaración de Río de 1992 y la Declaración del Milenio de 2000, los gobiernos han acordado principios fundamentales que son cruciales para las relaciones nacionales e internacionales» ${ }^{20}$.

El proceso evolutivo nos revela que numerosos instrumentos políticojurídicos se han ocupado del contenido de los ODS y, también, de la noción de desarrollo sostenible y sus implicaciones en la sociedad internacional. Se trata, por ello, de descubrir qué alcance tienen estos instrumentos y qué valor hay que otorgar, también desde la óptica jurídica, a la posición que mantienen a este respecto los Estados y otros actores relevantes en la escena internacional. La definición de desarrollo sostenible o, por lo menos, de los principales elementos que conforman esta noción es muy útil en la configuración de la arquitectura de la sociedad internacional del siglo XXI si que quieren hacer efectivos los objetivos y metas que ha recogido la Agenda 2030. El ordenamiento jurídico internacional no es ajeno a esta cuestión.

En definitiva, la evolución del concepto de desarrollo sostenible demuestra dos realidades: Primera, el desarrollo sostenible es una «noción acumulativa» que se ha ido enriqueciendo con componentes políticos, sociales y normativos a lo largo del tiempo. Esta acumulación aporta muchos elementos de incertidumbre y de comprensión de la propia noción e impide que disponga de rasgos claros. Segunda, el desarrollo sostenible es una «noción dependiente» que precisa de la existencia de ciertos principios del orden internacional para que produzca determinados efectos jurídicos. El desarrollo sostenible carece de autonomía en muchos ámbitos y sólo despliega efectos por la presencia simultánea de principios que regulan las diferentes materias de las que se ocupa.

Es necesario, no obstante, prestar la debida atención a esta evolución. Lo decía el Secretario General de las Naciones Unidas, B. B. GHALI, para quien «la fragmentación del tercer mundo que hace aparecer una multiplicidad de situaciones diferenciadas, la metamorfosis de los países del Este y su integración en los circuitos económicos mundiales, la aparente victoria de la economía de mercado tanto en el aspecto normativo como en el práctico,

20 Martens, J., «Hacia un marco de objetivos universales de sostenibilidad como parte de una agenda post-2015, la agenda de desarrollo post-2015: ¿más de lo mismo o el principio de la transición?», Economistas Sin Fronteras, Dossieres EsF, nº 11 (septiembre de 2013). 
transforman profundamente las relaciones económicas internacionales y nos imponen renovar nuestras maneras de pensar el desarrollo. Pero no basta con forjar un nuevo pensamiento internacional del desarrollo. También hace falta que la Comunidad internacional se dote de los medios de llevarlo a cabo. Precisamente a la Organización de las Naciones Unidas le corresponde recordar a cada Estado -tanto a los países industrializados como a los países en desarrollo- la exigencia de sus deberes $\gg^{21}$.

\section{LA CONFIGURACIÓN DEL PRINCIPIO DE DESARROLLO SOSTENIBLE}

Conviene preguntarse si el concepto de desarrollo sostenible, desde la proclamación de los ODS, ha iniciado, por fin, el camino hacia su consagración como un principio estructural del orden internacional o si, por el contrario, esta proclamación es todavía insuficiente para lograr que el desarrollo sostenible ocupe un lugar «constitucional». Habría que preguntarse, también, si los ODS fortalecen esta noción en el orden internacional y facilitan, por tanto, su afirmación como principio fundamental. Habría que preguntarse, por último, si es necesario que exista un principio esencial relativo al desarrollo sostenible para que se cumplan los ODS o sólo cuando se constate este cumplimiento tendremos la certeza de que ha surgido y se ha consolidado dicho principio.

El carácter evolutivo de la noción de desarrollo sostenible nos indica que debe entenderse, con toda seguridad, como un valor propio de la comunidad internacional y, con muchas más dificultades, como un incipiente principio del orden jurídico internacional.

i) La paz, el desarrollo, los derechos humanos y la democracia están presentes, como valores, en la configuración del sistema internacional contemporáneo. En particular, el desarrollo es uno de los principales valores que inspiran a la sociedad internacional. Numerosos instrumentos político-jurídicos confirman que el desarrollo sostenible forma parte de los valores de la comunidad internacional. Ha quedado reflejado en instrumentos muy relevantes. En la Declaración de Estocolmo sobre el Medio Humano, de 1972 se sostenía que «la protección y mejoramiento del medio humano es una cuestión fundamental que afecta el

21 Acto de investidura de Boutros-GHali, Universidad Carlos III de Madrid, 1994, p. 22. 
bienestar de los pueblos y al desarrollo económico del mundo entero, un deseo urgente de los pueblos de todo el mundo y un deber de todos los gobiernos». Se establecía, asimismo, como Principio 8 que «el desarrollo económico y social es indispensable para asegurar al hombre un ambiente de vida y trabajo favorable y crear en la Tierra las condiciones necesarias para mejorar la calidad de la vida». El principio 1 de la Declaración de Río sobre Medio Ambiente y Desarrollo, en 1992, dejaba claro que «los seres humanos constituyen el centro de las preocupaciones relacionadas con el desarrollo sostenible. Tienen derecho a una vida saludable y productiva en armonía con la naturaleza». También, en la Declaración del Milenio, del 2000, dentro del respeto a la naturaleza como valor fundamental para las relaciones internacionales en el siglo XXI, se afirma que «es necesario actuar con prudencia en la gestión y ordenación de todas las especies vivas y todos los recursos naturales, conforme a los preceptos del desarrollo sostenible». Por último, en el Documento Final de la Conferencia sobre Desarrollo Sostenible, de 2012, se comienza renovando el «compromiso en pro del desarrollo sostenible y de la promoción de un futuro económico, social y ambientalmente sostenible para nuestro planeta y para las generaciones presentes y futuras $\gg^{22}$.

La afirmación del desarrollo como un valor propio y singular de la sociedad internacional de nuestro tiempo ha recibido numerosas adhesiones y, al mismo tiempo, se han derrochado muchos esfuerzos para hacer efectivos los objetivos que se derivan de la afirmación de un valor de esta índole. La cuestión central es, sin embargo, determinar si se ha producido el salto de la noción de desarrollo, como valor fundamental de la sociedad internacional, a su consideración como principio estructural del orden internacional. Ello implicaría sobrepasar los meros compromisos políticos y penetrar, con intensidad, en el marco de las obligaciones internacionales no sólo para los Estados sino, también, para el resto de los actores afectados por las consecuencias de un desarrollo sostenible $^{23}$. Pero, también, habría que determinar si el desarrollo ha alcanzado

22 En la Resolución de la A.G. 70/1 «se dice que «en nombre de los pueblos a los que servimos, hemos adoptado una decisión histórica sobre un amplio conjunto de Objetivos y metas universales y transformativos, de gran alcance y centrados en las personas. Nos comprometemos a trabajar sin descanso a fin de conseguir la plena implementación de la presente Agenda de aquí a 2030. Reconocemos que la erradicación de la pobreza en todas sus formas y dimensiones, incluida la pobreza extrema, es el mayor desafío a que se enfrenta el mundo y constituye un requisito indispensable para el desarrollo sostenible», párr. 2.

23 Para V. Claerebout «le développement durable est un objectif, qui peut constituer l'objet et le but des traités et instruments juridiques internationaux. Il est à notre sens inexact de le considérer comme un principe juridique. «L'agenda 21 emploie le terme «principe d'action», qui 
un cierto grado de autonomía conceptual y normativa que le permita formar parte de esos principios.

Por lo menos, la noción de desarrollo es un valor que tiene consecuencias de naturaleza política en la escena internacional y que se constituye, con certeza, en unos de los principales propósitos de la comunidad internacional en su conjunto. Más allá de la ingente labor realizada por las Naciones Unidas ${ }^{24}$ y su papel principal, el concepto de desarrollo sobrepasa estos límites y ha penetrado en el espacio consuetudinario en el que habitan los «principios constitucionales» del orden internacional sin que todavía esté clara su significación en este campo y, sobre todo, el alcance y contenido del que se ha dotado a estos efectos.

ii) El carácter del orden jurídico internacional y, sobre todo, el lento y pausado proceso de formación de las normas jurídicas favorecen y propician que un eventual «principio de desarrollo» no encuentre perfecto acomodo. La eventual consagración de un principio relativo al desarrollo sostenible encuentra cabida plenamente en esta reflexión. La comunidad internacional viene afirmando su adhesión al desarrollo y, sin embargo, no es fácil encontrar obligaciones precisas y exigibles que se deriven de un «principio» de esta índole. La proclamación de los 17 ODS implica un mecanismo práctico que no asegura que el desarrollo sostenible se afirme como principio fundamental ${ }^{25}$. Desde esta óptica, la noción de desarrollo sostenible traduciría, al menos, los siguientes aspectos:

Por un lado, los ODS adquieren sentido por la existencia de profundas desigualdades en la sociedad internacional. Estas desigualdades permanecen y per-

éloigne le concept du sens juridique pour se limiter à l'idée d'une ligne directrices de l'action à mener, et/ou de l'encadrement de cette action». La CIJ ne se réfère pas au développement durable en tant que principe, mais bien en tant que concept, notamment dans l'affaire Gabcikovo-Nagymaros (...)», CLAEREBOUT, V., Le développement durable en droit international: mise en cevre juridique et instrumentalisation du concept, Université de Nice, 2011.

24 Rodrigo, A. J., El desarrollo sostenible como uno de los propósitos de las Naciones Unidas, cit.

25 En efecto, «un campo especialmente abonado a la utilización de instrumentos de soft law es el del desarrollo sostenible. La recurrente falta de acuerdo, la dificultad para el acercamiento de posiciones enfrentadas tanto desde el punto de vista económico como desde el medioambiental, y la existencia de instituciones flexibles y poco consolidadas, abocan a utilizar mecanismos que per se no tienen fuerza vinculante, como es el caso de resoluciones, declaraciones, programas, estrategias, códigos de conducta, informes, etc., todos ellos ágiles y dúctiles, aunque no seguros legalmente hablando», CHicharro, A., «El carácter de soft law de los instrumentos internacionales sobre desarrollo sostenible», Desafíos de los Estudios del Desarrollo, Actas del I Congreso Internacional de Estudios del Desarrollo, Santander, 14-16 de noviembre de 2012, Red Española de Estudios del Desarrollo, mayo 2013, p. 1016. 
viven y, en algunos sectores, se acrecientan e, incluso, se manifiestan de una manera más intensa y desgarradora. La desigualdad está en las esencias de la sociedad internacional y encuentra manifestaciones en todos los ámbitos de las relaciones internacionales. Ciertos sectores presentan, no obstante, mayores componentes de desigualdad. En la formulación de los ODS, la desigualdad tiene, además, un enfoque integral y no sólo se refiere a los Estados sino, también, a los individuos. Así lo expresó la delegación de los Estados Unidos al decir que «a pesar de promover avances notables, los Objetivos de Desarrollo del Milenio dejaron caer en el olvido a grandes sectores clave de la población, e incluso a países enteros. El énfasis de esta Agenda en no dejar a nadie rezagado y en asegurar el progreso para los más vulnerables constituye un cambio notable y decisivo. Nos complace observarlo. Acogemos con beneplácito su hincapié especial en la inclusión de todos los grupos y todas las personas (...)» ${ }^{26}$. La desigualdad, por lo tanto, debe formar parte del análisis que conduzca al logro de los ODS y ha de constituir un punto clave en la consecución de los objetivos y metas que se han señalado. Pero, al mismo tiempo, la desigualdad es una realidad a tener en cuenta en la configuración político-jurídica de la noción de desarrollo. Está claro que, en las relaciones económicas internacionales, «tal y como en la actualidad están organizadas», al hecho de la interdependencia se añade «la cualificación de la desigualdad. Interdependencia y desigualdad aparecen así como las coordenadas más significativas de la economía mundial contemporánea ${ }^{27}$.

Por otro lado, el cumplimiento de los ODS sólo es posible con la participación de todos los actores que, en la actualidad, conforman e integran la sociedad internacional. La Agenda para el 2030 señala la importancia de la participación de múltiples actores en la consecución de los Objetivos ${ }^{28}$. Hace tiempo, lo

26 Asamblea General de las Naciones Unidas, A/69/PV.101, p. 26.

27 Abellan Honrubia, V., «Algunas consideraciones sobre el Nuevo Orden Económico Internacional», R.F.D.U.C., ONU año XL, Madrid, 1987, p. 217.

28 En particular, en la Resolución 70/1 se dice que «los nuevos Objetivos y metas entrarán en vigor el 1 de enero de 2016 y guiarán las decisiones que adoptemos durante los próximos 15 años. Todos trabajaremos para implementar la Agenda dentro de nuestros propios países y en los planos regional y mundial, teniendo en cuenta las diferentes realidades, capacidades y niveles de desarrollo de cada país y respetando sus políticas y prioridades nacionales. Respetaremos también el margen normativo nacional para un crecimiento económico sostenido, inclusivo y sostenible, particularmente en los países en desarrollo, pero siempre de manera compatible con las normas y los compromisos internacionales pertinentes. Reconocemos además la importancia que para el desarrollo sostenible tienen las dimensiones regionales y subregionales, la integración económica regional y la interconectividad. Los marcos regionales y subregionales pueden 
señaló, también, el Secretario General, Kofi Anan, para quien «en el proceso actual de creciente mundialización, ninguna de las cuestiones críticas con que nos enfrentamos puede resolverse en un ámbito exclusivamente nacional. Todas requieren la cooperación, la asociación y un reparto de tareas entre los gobiernos, las Naciones Unidas, las organizaciones regionales, las organizaciones no gubernamentales, el sector privado y la sociedad civil. Las Naciones Unidas han desplegado considerables esfuerzos para forjar asociaciones mundiales que promuevan los intereses internacionales, pero necesitamos profundizar aún más ese proceso» ${ }^{29}$. Esta necesidad resulta acuciante para los Estados, pero supone también la implicación de los individuos, los pueblos y, por supuesto, las Organizaciones Internacionales. En el Documento Final de la Conferencia de Naciones Unidas sobre Desarrollo Sostenible, de 2012, se afirma, con claridad, el valor de «la diversificación de los actores y los interesados que se dedican a la búsqueda del desarrollo sostenible». Aunque se destaca la «necesaria participación plena y efectiva de todos los países, en particular los países en desarrollo, en la adopción de decisiones a nivel mundial» ${ }^{30}$.

La participación de múltiples actores en la consecución de los ODS ayudará a reforzar la noción de desarrollo sostenible como un principio estructural del orden internacional, aunque seguirá siendo preciso contar con la voluntad de los Estados. La debilidad para alcanzar los objetivos y las metas que se han indicado en la Agenda 2030 radica, precisamente, en que se carece de la

hacer que sea más fácil traducir efectivamente las políticas de desarrollo sostenible en medidas concretas a nivel nacional», párr. 22. Para J. A. Sanahuja, «la propuesta de objetivos post-2015 representa un gran avance como propuesta de -pacto global para el desarrollo-. Resitúa en un marco multilateral, más representativo y legítimo, la definición de las metas globales, con las coaliciones de poder tradicionales en una posición menos relevante que en el pasado», De los objetivos del milenio al desarrollo sostenible, cit., p. 78.

29 Memoria del Secretario General sobre la labor de la Organización, Suplemento nº 1 (A/56/1), Nueva York, 2001, párrafo 11.

30 En realidad, «la única forma de garantizar que la Agenda Post-2015 y los ODS se cumplan a nivel nacional es asegurando la participación de la sociedad civil y de todos los otros actores involucrados (academia, comunidad científica y sector privado) en los procesos de toma de decisión y en e 1 proceso general de implementación. Como lo ha mencionado el Secretario General de Naciones Unidas, esta agenda exige una línea de acción verdaderamente participativa, receptiva y transformadora. Por ende, es necesario que los países garanticen espacios donde los ciudadanos puedan enterarse de qué está pasando tanto a nivel internacional como nacional y regional, y de igual modo, encuentren una plataforma de debate público donde se analice el proceso desde diferentes puntos de vista. El proceso de implementación de la agenda es de todos, y la forma como comuniquemos la misma es también un reto importante que se debe asumir», $A B C$ de los objetivos de desarrollo sostenible, cit., p. 23. 
voluntad decidida de los Estados. En manos de los Estados está, por lo tanto, convertir el desarrollo sostenible no sólo en un objetivo prioritario y un valor imprescindible de la comunidad internacional sino, también, en un principio fundamental del que procedan obligaciones específicas y que entrañe responsabilidad internacional.

En suma, «se han producido cambios profundos, sobre todo desde el fin de la guerra fría, que ponen en tela de juicio algunas de las formas habituales de hacer frente a los desafíos del desarrollo» ${ }^{31}$. Ahora bien, queda claro que el desarrollo es uno de los objetivos primordiales de la actual comunidad internacional. Las primeras expresiones del Programa de Desarrollo destacaban, precisamente, que «el desarrollo constituye una de las principales prioridades de las Naciones Unidas. El desarrollo es una empresa multidimensional para lograr una mejor calidad de vida para todos los pueblos. El desarrollo económico, el desarrollo social y la protección del medio ambiente son componentes del desarrollo sostenible que tienen una relación de interdependencia y se refuerzan recíprocamente ${ }^{32}$. Para ello se ha realizado una incesante labor normativa que ha ido produciendo como fruto la adopción de instrumentos jurídicos, de desigual valor, en favor del desarrollo. Dichos instrumentos, que han ido perfilando los elementos centrales de la noción de desarrollo sostenible, lo han ido concibiendo en sus diferentes dimensiones y han ido diseñando ámbitos diversos en los que podría producir efectos.

Los ODS, como última expresión de la voluntad de la comunidad internacional por eliminar la pobreza y asegurar el bienestar del ser humano, han contribuido a fortalecer el concepto de desarrollo sostenible y lo van acercando a la categoría de principio «constitucional» del orden internacional. Pero la conformación de un «orden constitucional internacional» precisa de la existencia de principios que tengan un carácter no sólo político sino, también, jurídico. La cuestión es decidir si, finalmente, el desarrollo sostenible ha alcanzado la naturaleza de principio jurídico y si reúne, en esencia, las características que definen a los principios estructurales del orden internacional. Los ODS pueden alcanzarse, aunque sea parcialmente, a pesar de que no se disponga de un principio fundamental. En otros términos, la propia formulación de los ODS se hace desde la perspectiva política y se asumen, por ello, compromisos de carácter eminentemente político. Los puntos 5 y 6 del Documento Final de la

31 Programa de Desarrollo, A/RES/51/240, 15 de octubre de 1997, párr. 5.

32 Ibid., párr. 1. 
Conferencia de Naciones Unidas sobre Desarrollo Sostenible de 2012, resumen muy bien la índole política de los ODS. En estos puntos se reafirma el «compromiso de hacer todo lo posible para acelerar el logro de los objetivos de desarrollo convenidos internacionalmente, incluidos los Objetivos de Desarrollo del Milenio para 2015». Y, además, se reconoce que «las personas constituyen el centro del desarrollo sostenible y a este respecto, nos esforzamos por lograr un mundo que sea justo, equitativo e inclusivo, y nos comprometemos a trabajar de consuno para promover el crecimiento económico sostenido e inclusivo, el desarrollo social y la protección del medio ambiente, lo que redundará en beneficio de todos».

Comoquiera que sea, el desarrollo sostenible, como término y concepto, ha avanzado significativamente en esta dirección. Desde la proclamación de la Declaración del Milenio en 2000, la comunidad internacional viene expresando, con toda intensidad, su compromiso con los componentes más relevantes del concepto de desarrollo sostenible y ello se ha acrecentado con la afirmación de los ODS, en 2015. Por esto, podemos apreciar algunos datos significativos:

En primer lugar, los principios fundamentales del ordenamiento jurídico internacional responden al cumplimiento de las funciones básicas de este ordenamiento. Los principios resumen los valores cuya defensa se asume y que están presentes en el comportamiento de la comunidad internacional ${ }^{33}$. Los diversos instrumentos que se han adoptado en relación con el desarrollo sostenible demuestran que es un valor en alza para los Estados, las Organizaciones Internacionales y para el resto de los actores que intervienen en las relaciones internacionales contemporáneas. Cuando determinados valores, que se consideran esenciales, se traducen jurídicamente y adoptan la forma de principios estructurales, asistimos al asomo de un «sistema constitucional implícito», pero inequívoco, constituido por principios y normas intangibles.

Prácticamente consagrado el derecho al desarrollo y afirmado el concepto de desarrollo sostenible, el fracaso se manifiesta tanto en la lentitud a la hora de poner en práctica normas internacionales en materia de desarrollo, como en la ausencia de una acción común que lleve al campo consuetudinario normas y principios cuya eficacia jurídica es limitada, por encontrarse, muchas veces,

33 Para J. Gonzalez Campos estos principios «expresan valores fundamentales que inspiran la estructura general de ese ordenamiento, en un determinado momento de su evolución histórica» e «informan el sistema jurídico en su totalidad», Curso de Derecho Internacional Público, Oviedo, 1983 , pp. 39 y 40. 
en resoluciones con carácter de recomendación ${ }^{34}$. Por esto, «es necesario que el derecho al desarrollo afirmado y reconocido sea explicitado por normas más precisas» ${ }^{35}$.

El desarrollo sostenible debería ser un principio del orden constitucional internacional. F. Mariño Menéndez, ha dicho que «dadas su universalidad, la importancia de su objeto y la amplitud de su intencionada "intensidad normativa", un principio así concebido tiene por fuerza que ser incluido entre los que integran la constitución material del ordenamiento internacional». Para este autor, «quienes afirman la vigencia del principio que impone la obligación de respetar el derecho al desarrollo también afirman la obligación de los Estados de cooperar para el desarrollo. Pero ello es así porque el principio de cooperación queda afectado por el nuevo principio y debe ser entendido en su interrelación con él, al igual que deben serlo todos los demás principios que, como se ha dicho, integran lo que puede denominarse <constitución material del ordenamiento internacional (...) $>\gg^{36}$.

En realidad, el desarrollo sostenible no forma parte todavía de los principios fundamentales del orden internacional pero se ha iniciado, desde hace tiempo, el camino para que adquiera naturaleza constitucional. Por lo menos, existe una estrecha vinculación entre el desarrollo y la comunidad internacional. La ha explicitado, por ejemplo, $M$. Flory, para quien «au règne exclusif de l'Etat souverain tendaient à se substituer les exigences d'une communnauté internationale solidaire qui s'efforçait d'élaborer des règles de fond por planifier le développement et imposer aux Etats des obligations d'aide et de coopération ${ }^{37}$.

En segundo lugar, la noción de desarrollo sostenible no goza de autonomía conceptual, política y normativa. Esto retrasa su configuración como principio fundamental del orden internacional. La noción de desarrollo sostenible expresa, en esencia, su estrecha vinculación con determinados principios del orden internacional y no logra, por ello, alcanzar su propia autonomía y conformarse como un principio propio y singular del ordenamiento jurídico

34 Barral V., «Sustainable Development in International Law: Nature and Operation of an Evolutive Legal Norm», The European Fournal of International Law, vol. 23 n 2 (2012), pp. 377 ss.

35 IsRaEL, J. J. «Le droit au développment», R.G.D.I.P. (1983), p. 27.

36 MariÑo MenÉnDEZ, F., «El marco jurídico internacional del desarrollo», en C. R. Fernández Liesa, y F. M. Mariño Menéndez (coords.), El Desarrollo y la Cooperación internacional, 1997, pp. 35-54.

37 Flory, M., «Mondialisation et Droit International du développement», R.G.D.I.P. (1997-3), p. 610 . 
internacional. En particular, la relación del desarrollo con el principio de la cooperación internacional, plenamente consagrado en el Derecho Internacional; con el principio de la protección internacional de los derechos humanos, asentado y aceptado por la comunidad internacional; y con el principio de la protección internacional del medio ambiente que se encuentra en fase de cristalización, es lo que condiciona la afirmación de que el desarrollo sostenible es un principio constitucional de este ordenamiento.

\section{a) Desarrollo y cooperación internacional}

El camino que conduce el desarrollo sostenible hacia la categoría de principio fundamental del orden internacional se está recorriendo y debe situarse en el marco de la solidaridad internacional. El objetivo de la sociedad internacional y de su ordenamiento jurídico está, en consecuencia, perfectamente delimitado y sólo faltan por precisar los medios, los procedimientos y los mecanismos para el logro de este objetivo. La única forma para que el sistema internacional se adapte a las nuevas realidades es profundizando en las solidaridades universales $^{38}$. De ahí, el nexo que siempre se ha establecido entre desarrollo y cooperación internacional. El desarrollo sería, entonces, una manifestación específica del principio fundamental de la cooperación internacional, asentado en el orden internacional desde mediados de los años setenta del siglo XX.

El desarrollo y la promoción del desarrollo adquieren distintos significados normativos y aparecen vinculados al principio de la cooperación internacional. La desigualdad en los niveles de desarrollo entre los Estados que conforman la comunidad internacional es escalofriante. No se han encontrado las fórmulas jurídicas para hacer frente, realmente y con eficacia, a los problemas que genera esta desigualdad y, mientras tanto, ésta subsiste con bastante intensidad. La acción en favor del desarrollo es un elemento imprescindible para eliminar la desigualdad y afirmar la existencia de ciertas «solidaridades» en la

38 Lo decía el Secretario General de las Naciones Unidas: «como resultado de la globalización, poco a poco se está empezando a comprender que el compromiso de todo el mundo para con los países pobres, responde, no sólo a un imperativo moral, sino también a un interés común. Cada país debe asumir la responsabilidad principal de sus propios programas de crecimiento económico y de reducción de la pobreza. Sin embargo, librar al mundo del azote constituido por la pobreza extrema es un desafío para cada uno de nosotros. Es un desafío al que tenemos ineluctablemente que responder», Informe sobre la Cumbre del Milenio (El Papel de las Naciones Unidas en el siglo XXI. Documentos Oficiales, Nueva York, 2000), <www.un.org/es/events/pastevents/ millennium_summit/sg_report/full.htm>, párr. 188. 
sociedad internacional sobre la base del principio de la cooperación internacional. En definitiva, la noción de desarrollo sostenible se vincula, también, al principio de la cooperación internacional pero, realmente, lo desborda. Por ello, este principio de la cooperación internacional es insuficiente para expresar el contenido, alcance y dimensiones, en su totalidad, del desarrollo sostenible.

\section{b) Desarrollo y protección internacional de los derechos humanos}

Estrechamente ligado a la defensa de los derechos humanos, el derecho al desarrollo expresa que las desigualdades económicas no deben plantearse exclusivamente en términos de relaciones inter-estatales, sino en el sentido más global e integrador que tiene como último punto de referencia al ser bumano ${ }^{39}$. El derecho al desarrollo es un derecho humano. La Declaración sobre el derecho al Desarrollo, de 1986, trata de positivar un derecho de esta índole. No sólo el Preámbulo de esta Declaración está anegado de referencias a los derechos humanos, sino que, también, el conjunto de su parte dispositiva diseña, como se dice en el párrafo 1 del artículo 2, el contenido del «derecho humano al desarrollo». El derecho al desarrollo es un derecho humano y se ejerce en el contexto de la protección internacional de los derechos humanos ${ }^{40}$.

39 Como nos recuerda A. Chueca Sancho, «hace aproximadamente dos décadas, la doctrina internacional comienza a hablar de un grupo de Derechos que no nacen ni de la tradición liberal ni de la tradición socialista; se trata de los derechos de la tercera generación o derechos de la solidaridad. Estos derechos pretenden responder a los principales retos a los que se enfrenta la Humanidad en el presente», El derecho al desarrollo en el ámbito internacional, Desarrollo, maldesarrollo y cooperación al desarrollo, Seminario de Investigación para la paz, Zaragoza, 1997, p. 27. Para el Secretario General de las Naciones Unidas, «la política de desarrollo no es sólo una cuestión económica en sentido estricto. El desarrollo no se da en el vacío. Requiere niveles mínimos de seguridad para el ser humano y debe comportar participación política y respeto de los derechos humanos», Memoria del Secretario General sobre la labor de la Organización, Nueva York, 1999, p. 20, párr. 145.

40 Como se señala el artículo 1, este derecho «es un derecho humano inalienable en virtud del cual todo ser humano y todos los pueblos están facultados para participar en un desarrollo económico, social, cultural y político en el que puedan realizarse plenamente todos los derechos humanos y libertades fundamentales, a contribuir a ese desarrollo y a disfrutar de el». Segunda, se sitúa a la persona bumana en el centro de la titularidad del derecho al desarrollo, con independencia de que sean también titulares otros entes. Por esta razón, el artículo 2 afirma categóricamente que «La persona humana es el sujeto central del desarrollo y debe ser el participante activo y el beneficiario del derecho al desarrollo». Por último, se deja claro que el incumplimiento en materia de derecho bumanos perjudica el ejercicio del derecho al desarrollo y, así, el artículo 6, párrafo 3 de la Declaración establece que «los Estados deben adoptar medidas para eliminar los obstáculos al desarrollo resultantes de la inobservancia de los derechos civiles y políticos, así como de los derechos económicos sociales y culturales». 
La Declaración de la Segunda Conferencia Mundial sobre Derechos Humanos, Viena 1993, supone un avance bastante significativo en esta materia. En el discurso inaugural de esta Conferencia, el Secretario General de las Naciones Unidas recordaba el vínculo existente entre democracia, desarrollo y derechos humanos, y sostenía que «una cosa es segura: no puede haber desarrollo duradero sin promoción de la democracia y, por ende, sin respeto de los derechos humanos» ${ }^{41}$. La Declaración de Viena, en su punto 8, establece la relación democracia, desarrollo y respeto de los derechos humanos, sobre la base de que «la comunidad internacional debe apoyar el fortalecimiento y la promoción de la democracia, el desarrollo y el respeto de los derechos humanos y de las libertades fundamentales en el mundo entero», y dedica íntegramente los puntos 10 y 11 a precisar el contenido del derecho al desarrollo en la línea marcada por la Declaración sobre el Derecho al Desarrollo.

No está tan claro, sin embargo, que el desarrollo y, en particular, el desarrollo sostenible, haya alcanzado su autonomía y que se afirme como un principio fundamental del orden internacional, a pesar del impulso que ha recibido desde el respeto y la protección de los derechos humanos ${ }^{42}$. Puede hablarse de un «desarrollo humano» amparado por normas internacionales de diversa naturaleza, que afectan a diferentes sectores de las relaciones internacionales, y con distintos destinatarios. Sin embargo, la situación normativa no está clara. No obstante, para A. Chueca Sancho «la positivación del derecho al desarrollo no es un fenómeno emergente sino consolidado. Estamos ante un derecho, formulado en términos jurídicos, regulado por el Derecho Internacional; la obligatoriedad jurídica de este derecho es además asumida (de un modo más o menos claro) por los Estados, las Organizaciones Internacionales e incluso

41 Conferencia Mundial de Derechos Humanos, Naciones Unidas, 1993, pp. 20-21. Esta posición del Sr. Boutros Ghali va quedar bien reflejada en el texto de la Declaración y en el Programa de Acción. Esto nos permite decir, con F. Mariño Menéndez, que el «Documento Final» de esta Conferencia «hace una vigorosa reafirmación del derecho al desarrollo como derecho universal e inalienable y como parte integrante de los derechos humanos fundamentales», MARIÑO MENÉNDEZ, F., Derecho Internacional Público. Parte General, Madrid, 1995, p. 196.

42 Para M. Pérez González, «una característica básica del derecho al desarrollo (...) es su autonomía, en el sentido de que es un derecho con consistencia propia y no una simple suma o aglomerado de derechos preexistentes, sin que ello suponga negar que tal derecho (...) constituye una mera dimensión de los derechos humanos y (...) una síntesis (...) de los diferentes derechos», PÉREZ GonZÁLEZ, M., «El derecho al desarrollo como derecho humano», El derecho al desarrollo o el desarrollo de los derechos, Instituto de Ciencias y Sociedad, Madrid, 1991, p. 86 (cursiva añadida). 
muchos individuos $»^{43}$. Pero todavía falta que se deriven obligaciones precisas de la formulación del derecho humano al desarrollo y que cuente con mecanismos específicos de garantía y protección. En cualquier caso, la afirmación del desarrollo sostenible como un derecho humano contribuiría a reforzar el vínculo con la protección internacional de los derechos humanos aunque no dotaría a la noción de desarrollo sostenible de la autonomía y singularidad que precisa como principio esencial del orden internacional.

\section{c) La estrecha relación entre desarrollo y medioambiente}

Esta relación ha permitido hablar, con propiedad, de desarrollo sostenible. Numerosos instrumentos internacionales señalan esta relación. Queda reflejada en el punto 17 de la Declaración de la Conferencia de Naciones Unidas sobre Desarrollo Sostenible de 2012, al reconocer «la importancia que revisten los tres Convenios de Río para el fomento del desarrollo sostenible y a este respecto instamos a todas las Partes a que cumplan íntegramente los compromisos contraídos en virtud del Convenio Marco de las Naciones Unidas sobre el Cambio Climático, el Convenio sobre la Diversidad Biológica y la Convención de las Naciones Unidas de Lucha contra la Desertificación en los Países Afectados por Sequía Grave o Desertificación, en particular en África, de conformidad con sus respectivos principios y disposiciones, así como a que tomen medidas eficaces y concretas en todos los niveles y a que intensifiquen la cooperación internacional». La protección internacional del medioambiente es un principio incipiente del orden internacional pero diferente, en su configuración y contenido, del eventual principio del desarrollo sostenible.

El desarrollo sostenible se concibe como una plasmación de la protección internacional del medio ambiente y uno de los aspectos prioritarios de dicha protección. El crecimiento económico y la lucha contra la pobreza no deben traer consigo el deterioro de los ecosistemas ni tampoco poner el riesgo la vida sobre el planeta. En efecto, «le monde dispose des outils nécessaires pour mettre fin à l'extrême pauvreté sous toutes ses formes, promouvoir la croissance économique et assurer la durabilité environnementale» ${ }^{44}$. De ahí nace

43 Chueca Sancho, A., El derecho al desarrollo, cit., p. 33. Algunos títulos: Juste Ruiz, J., «El desarrollo sostenible y los derechos humanos», Soberanía del Estado y Derecho Internacional, Homenaje al Profesor 7. A. Carrillo Salcedo, Sevilla, 2005, pp. 757-778; MCGoldRJCK, D., «Sustainable development and human rights: An integrated approach», I.C.L.Q. (1996), pp. 796-818.

44 Lan, X.; Sachs, J. D.; Schmidt-Traub, G. y Tubiana, L., Définir des objectifs..., cit. 
la noción de desarrollo sostenible que, desde esta perspectiva, queda condicionada por el conjunto de normas que se han elaborado en materia de protección internacional del medioambiente. Los ODS se formulan desde esta premisa y suponen una idónea vinculación entre desarrollo y protección del medio ambiente que queda reflejada en numerosas ocasiones. El punto 9 de la Resolución 70/1 de la A.G. de 2015, indica la aspiración por «un mundo en el que cada país disfrute de un crecimiento económico sostenido, inclusivo y sostenible y de trabajo decente para todos; un mundo donde sean sostenibles las modalidades de consumo y producción y la utilización de todos los recursos naturales, desde el aire hasta las tierras, desde los ríos, los lagos y los acuíferos hasta los océanos y los mares; un mundo en que la democracia, la buena gobernanza y el estado de derecho, junto con un entorno nacional e internacional propicio, sean los elementos esenciales del desarrollo sostenible, incluidos el crecimiento económico sostenido e inclusivo, el desarrollo social, la protección del medio ambiente y la erradicación de la pobreza y el hambre; un mundo en que el desarrollo y la aplicación de las tecnologías respeten el clima y la biodiversidad y sean resilientes; un mundo donde la humanidad viva en armonía con la naturaleza y se protejan la flora y fauna silvestres y otras especies de seres vivos».

Pero ni la protección internacional del medio ambiente ni el desarrollo sostenible han llegado a ser principios fundamentales del orden internacional. La vinculación entre las dos realidades ha dado fuerza y ha impulsado la noción de desarrollo sostenible que constituye el fundamento de los ODS. La idea central que late tras estos Objetivos es, con seguridad, la consecución del desarrollo sostenible que implica el respeto y la protección del medio ambiente en todas sus dimensiones. La propia Cumbre de Río, en 1992, estableció la relación entre desarrollo y medioambiente. A partir de ahí, se vincularon dos tendencias que venían evolucionando en la sociedad internacional y que suponían la instauración de principios autónomos en el orden internacional. El desarrollo sostenible representa, por lo tanto, la síntesis de dos principios, aún no consagrados, pero en proceso de formación.

Los ODS quizá constituyan el último escalón que conduzca a la afirmación del desarrollo sostenible como principio fundamental. Algo se deduce del punto 5 de la Resolución 70/1 cuando afirma que «la presente Agenda tiene un alcance y una importancia sin precedentes. Todos los países la aceptan y se aplica a todos ellos, aunque teniendo en cuenta las diferentes realidades, capacidades y niveles de desarrollo de cada uno y respetando sus políticas y prioridades nacionales». La aceptación y el cumplimiento por parte de los Es- 
tados será, al final, el factor que determine que se ha culminado el proceso que conduce el desarrollo sostenible a la categoría de principio «constitucional» del orden internacional.

En esencia, la larga evolución de la noción de desarrollo sostenible continúa y no hay que menospreciar los relevantes logros que se han alcanzado tanto en la lucha contra la pobreza como, en concreto, en el marco de la protección internacional del medio ambiente así como en todos aquellos sectores que quedan cubiertos bajo dicha noción. No obstante, el desarrollo sostenible no ha alcanzado todavía el estadio en el que se afirme su condición de principio estructural. La proclamación de los ODS así como la formulación, en su momento, de los ODM han contribuido, de manera decisiva, al impulso para la consagración del desarrollo sostenible como un principio «constitucional». Los diversos instrumentos internacionales que confirman la aceptación universal del desarrollo sostenible son, asimismo, la base para que se asiente, definitivamente, como principio fundamenta ${ }^{45}$.

\section{Principales dimensiones Del Desarrollo sostenible}

La práctica internacional revela que la noción de desarrollo ha ido incorporando paulatinamente diversos componentes. Los diferentes instrumentos internacionales han ido poniendo el énfasis en uno u otro de los aspectos que, en la actualidad, definen a esta noción. La incorporación de esos elementos ha otorgado al desarrollo sostenible una naturaleza compleja y ha hecho difícil su definición. La aceptación del término desarrollo sostenible supone, pues, el triunfo de esa acumulación que tiene consecuencias políticas y normativas.

El carácter multidimensional del desarrollo queda patente en los instrumentos político-jurídicos que abordan esta cuestión y que se han adoptado en ámbitos muy diferentes ${ }^{46}$. Más aún, «beyond these essential components of sus-

45 El punto 10 de la Resolución 70/1, afirma que «la nueva Agenda se inspira en los propósitos y principios de la Carta de las Naciones Unidas, incluido el pleno respeto del derecho internacional. Sus fundamentos son la Declaración Universal de Derechos Humanos, los tratados internacionales de derechos humanos, la Declaración del Milenio y el Documento Final de la Cumbre Mundial 2005. Se basa asimismo en otros instrumentos, como la Declaración sobre el Derecho al Desarrollo».

46 Por citar algunos ejemplos, no se pueden situar en el mismo espacio normativo ciertas resoluciones en las que se reconoce, con claridad, este derecho y entre las que destaca, sin duda, la Resolución 41/128 de la Asamblea General de las Naciones Unidas, de 4 de diciembre de 1986, titulada 
tainable development, a vast array of legal standards and principles is further closely connected to its realization. When implemented, these participate in the integration of environmental protection and economic and social development, and thus help to achieve sustainable development ${ }^{47}$.

Para A. J. RodRigo Hernández, el concepto de desarrollo sostenible tiene «una pluralidad de dimensiones, algunas de ellas no necesariamente incompatibles entre sí. Este carácter multidimensional de la noción permitiría explicar el desarrollo sostenible como un objetivo político de primera magnitud tanto en el plano internacional como en el estatal y el local (...) $\gg^{48}$. La práctica internacional ha confirmado esta posición y no ha dejado de señalar, con reiteración, que el logro del desarrollo sólo es factible con el cumplimiento de sus tres dimensiones fundamentales. La Declaración de Naciones Unidas sobre Desarrollo Sostenible, de 2012, sostiene, con fuerza, que «es necesario incorporar aun más el desarrollo sostenible en todos los niveles, integrando sus aspectos económicos, sociales y ambientales y reconociendo los vínculos que existen entre ellos, con el fin de lograr el desarrollo sostenible en todas sus dimensiones».

Los aspectos del desarrollo son numerosos o, por lo menos, este fenómeno se puede abordar desde diferentes perspectivas. El desarrollo, como se dice en la Declaración sobre el Derecho al Desarrollo, «es un proceso global económico, social, cultural y político, que tiende al mejoramiento constante del bienestar de toda la población y de todos los individuos sobre la base de su participación activa, libre y significativa en el desarrollo y en la distribución justa de los beneficios que de él se derivan». Ahora bien, sería equivocado contemplar el desarrollo de una manera parcial o fragmentada, ya que todos los elementos

\footnotetext{
«Declaración sobre el Derecho al Desarrollo», pero a la que habría que añadir resoluciones adoptadas, durante el decenio de los setenta, como la Resolución 3201 (S-vI) que contiene la Declaración relativa al establecimiento de un Nuevo Orden Económico Internacional, de 1 de mayo de 1974 o la Resolución 3281 (XXIX) que contiene al Carta de los Derechos y los Deberes Económicos de los Estados, de 12 de diciembre de 1974; o la Resolución S-18/3 relativa a la Declaración sobre la cooperación económica internacional. Pero, también, podríamos recordar, desde otra perspectiva, muchas otras resoluciones que enmarcan la cuestión del desarrollo en el Derecho Internacional, tales como la Resolución 1515 (xv), sobre una acción concertada en pro del Desarrollo; o las Resoluciones 1710 (XVI), 2626 (XXV), 35/56 y 45/1999 en las que se establecen los decenios de Naciones Unidas para el desarrollo.

47 Barral, V., «Sustainable Development...», cit., p. 381.

48 Rodrigo Hernández, A. J., «El concepto de desarrollo sostenible en el derecho internacional», Agenda ONU: Anuario de la Asociación para las Naciones Unidas en España, nº 8 (2006-2007), p. 162 .
} 
que definen el derecho al desarrollo están indisolublemente unidos, motivo por el que, en la citada Declaración, se estipula, en su artículo 9, que «Todos los aspectos del derecho al desarrollo (...) son indivisibles e interdependientes y cada uno de ellos debe ser interpretado en el contexto del conjunto de ellos».

Se han afirmado básicamente tres dimensiones del desarrollo sostenible ${ }^{49}$, como concepto básico de la actual sociedad internacional, que expresan la voluntad de promocionar el desarrollo y que contribuyen, de manera notable, a eliminar los elementos de insolidaridad en esta sociedad. Estas dimensiones, pueden contribuir a la afirmación del principio del desarrollo sostenible o, en su caso, reforzar la posición del desarrollo sostenible como un valor de carácter programático para que adquiera una mayor efectividad. En verdad, «la noción de desarrollo sostenible (...) es el resultado de un proceso evolutivo en el que han confluido sus tres pilares, (...): el desarrollo económico, el desarrollo social y la protección del medio ambiente. Estos tres componentes son complementarios, interdependientes y están interrelacionados entre sí, cada uno de ellos es un objetivo parcial y requisito imprescindible para la consecución de los demás y del objetivo global del desarrollo sostenible $\gg^{50}$.

Así lo expresa la Resolución 70/1 respecto a los ODS, al decir que «los 17 Objetivos de Desarrollo Sostenible y las 169 metas que anunciamos hoy demuestran la magnitud de esta ambiciosa nueva Agenda universal. Con ellos se pretende retomar los Objetivos de Desarrollo del Milenio y conseguir lo que estos no lograron. También se pretende hacer realidad los derechos humanos de todas las personas y alcanzar la igualdad entre los géneros y el empoderamiento de todas las mujeres y niñas. Los Objetivos y las metas son de carácter integrado e indivisible y conjugan las tres dimensiones del desarrollo sostenible: económica, social y ambiental».

No podemos limitar, por lo tanto, la noción de desarrollo sostenible, sobre sus efectos en el plano internacional, a ninguno de los componentes que hemos señalado y, en modo alguno, se puede equiparar este concepto exclusivamente con la protección internacional del medio ambiente. En efecto, «el desarrollo sostenible no es sólo la protección del medio ambiente, es una

49 Algunos autores han apuntando la existencia de cuatro principios. «Le cadre pour le développement durable décrit l'engagement de la société en faveur de Quatre objectifs interdépendants: le développement économique (notamment la fin de l'extrême pauvreté), l'inclusion sociale, la durabilité environnementale et la bonne gouvernance (notamment la sécurité)», LAN, X.; SACHS, J. D.; Schmidt-Traub, G. y Tubiana, L., Définir des objectifs..., cit.

50 Rodrigo HernándeZ, A. J., «El concepto de desarrollo sostenible...», cit., pp. 174-175. 
nueva forma de pensar sobre la vida y la política, es un tipo de crecimiento económico sostenible en armonía con la naturaleza, es la reanudación de los conceptos de justicia, oportunidad y igualdad entre todos los hombres $\gg^{51}$. De ahí que la afirmación de, al menos, tres dimensiones del desarrollo sostenible y, en consecuencia, de los ODS, impregnará todos los compromisos, políticas y programas que se ejecuten en esta materia. Es un enfoque global y universal en el que no se descuidan los aspectos más relevantes del desarrollo. Según la Resolución 70/1: «los presentes Objetivos y metas son universales y afectan al mundo entero, tanto a los países desarrollados como a los países en desarrollo, son de carácter integrado e indivisible y conjugan las tres dimensiones del desarrollo sostenible».

La evolución de la noción de desarrollo sostenible ha propiciado un marco muy amplio en el que no será fácil determinar las consecuencias políticas y jurídicas de una noción de este tipo. En realidad, «la noción de desarrollo sustentable es intrínsecamente compleja y su aplicación obliga a los gobiernos a pensar de manera relativamente diferente a lo que han estado habituados $\gg^{52}$. El examen de los instrumentos internacionales que recogen esta noción nos lleva a concluir que, unas veces, derivan compromisos de naturaleza meramente política y, otras veces, es posible advertir ciertas obligaciones de carácter jurídico.

La combinación de las tres dimensiones puede propiciar, en algunos casos, la existencia de una norma y la aparición de principios sectoriales que inspiran y constriñen el comportamiento de los Estados. Los diversos instrumentos político-jurídicos que han abordado el desarrollo han ido señalando estos principios $^{53}$. Los enfoques pueden ser muy diferentes y, desde la perspectiva

51 Para G. de Vincentiis, «los objetivos de desarrollo sostenible no son sólo cuantitativos sino también cualitativos. Una sociedad que se encuentra en una fase de desarrollo económico experimenta una serie de cambios: un aumento de la utilidad individual y la mejora o el mantenimiento de las libertades existentes. Una política de desarrollo sostenible extiende estos objetivos en una dimensión más amplia del tiempo, garantizando la calidad y la riqueza de la vida a las generaciones futuras», DE VINCENTIIS, G., «La evolución del concepto de desarrollo sostenible, Medio Ambiente y Derecho», Revista Electrónica de Derecho Ambiental, nº 23 (2012).

52 Boyle, A., «Derecho internacional y desarrollo sustentable», Revista de Estudios internacionales, vol. 37, nº 147 (2004), p. 10.

53 Se propusieron ocho principios «como una base normativa para una futura agenda de desarrollo», Grupo de Reflexión de la Sociedad Civil sobre Perspectivas Globales de Desarrollo, Hacia un marco de Objetivos Universales de Sostenibilidad como parte de una Agenda Post-2015, Documento de Reflexión, 19 de marzo 2013. Los principios de «precaución» y «quien contamina paga» pueden producir efectos jurídicos, DE VINCENTIIS, G., «La evolución del concepto...», cit. 
doctrinal, se puede poner el énfasis en unos u otros de los principios sectoriales que conforman la noción de desarrollo sostenible ${ }^{54}$. Lo relevante es que «el desarrollo sostenible ofrece también algunos principios y reglas de carácter sustantivo de diferente alcance y valor normativo para la elaboración de políticas públicas y de normas jurídicas internacionales que contribuyan a dicho objetivo». Entre estos principios se ha señalado, «el principio de integración de los aspectos económicos, sociales y ambientales que exige que tales dimensiones sean tenidas en cuenta en los procesos de adopción y aplicación de las decisiones políticas y de las normas jurídicas internacionales» ${ }^{55}$.

La combinación, por lo tanto, de las tres dimensiones básicas del desarrollo sostenible no tiene sólo un contenido teórico sino que produce efectos en la práctica tanto a la hora de implementar políticas y programas de desarrollo como en la imposición de obligaciones de índole jurídica. Por lo menos, las consecuencias de la definición completa de desarrollo sostenible facilitan a los Estados, como poco, guías de conducta y objetivos que se deben alcanzar. El contenido de la Resolución 70/1 apunta en esta dirección y propone un plan de actuaciones en el que se entremezclan las diversas dimensiones del desarrollo sostenible. En el punto 13 de la Declaración se afirma que «el desarrollo sostenible parte de la base de que la erradicación de la pobreza en todas sus formas y dimensiones, la lucha contra la desigualdad dentro de los países y entre ellos, la preservación del planeta, la creación de un crecimiento económico sostenido, inclusivo y sostenible y el fomento de la inclusión social están vinculados entre sí y son interdependientes».

Está claro el carácter complementario de las tres dimensiones del desarrollo sostenible. La incorporación conjunta de estas dimensiones trae consigo una evolución en el orden internacional y propicia la existencia de enfoques mucho más amplios. La noción de desarrollo sostenible abre las puertas a nuevas ramas del ordenamiento jurídico internacional en las que confluyen aspectos de diversa naturaleza. Los ODS se proyectan, también, en esta línea y han creado un espacio propio y autónomo en el que adquieren sentido sectores específicos del orden internacional. Sin duda, la Declaración de Río, de 1992, representa «un hito que señala la transición desde el derecho internacional ambiental y el derecho internacional económico hacia un derecho interna-

\footnotetext{
54 Un examen muy detallado en Rodrigo HernándeZ, A. J., El desafío del desarrollo sostenible, cit., pp. 95 ss.

55 Rodrigo HernándeZ, A. J., «El concepto de desarrollo sostenible...», cit., p. 200.
} 
cional del desarrollo sustentable $\gg^{56}$. En la actualidad, el enfoque de desarrollo sostenible ha penetrado en las reglas y normas que regulan el Derecho Internacional Económico así como en las pautas de conducta y los principios que tiene en cuenta la protección internacional del medio ambiente. Asimismo, queda establecida la vinculación del desarrollo sostenible con la protección internacional de los derechos humanos ${ }^{57}$.

En definitiva, la incorporación de, al menos, tres dimensiones al concepto de desarrollo produce unas consecuencias prácticas de primer orden. Por un lado, facilita la adopción de criterios que sirvan para el logro de los objetivos y metas que quedan reflejados en la Agenda 2030. Con seguridad, ofrece un marco conceptual, político y normativo que, más allá de la existencia o no de obligaciones precisas, impone principios, códigos de conducta, pautas y objetivos. Con ello, se hace realidad el compromiso «de trabajar sin descanso a fin de conseguir la plena implementación de la presente Agenda de aquí a 2030». Por otro lado, permite que el desarrollo se conciba de manera completa e integrada y que los objetivos y metas, que se incluyen en la Resolución 70/1, puedan alcanzarse a través de los mecanismos más apropiados. La función del orden internacional será determinante pues «el objetivo en la actualidad debe ser no tanto determinar el significado, alcance y naturaleza del concepto de desarrollo sostenible sino identificar cómo puede ser implementado por medio del Derecho internacional ${ }^{58}$. Por último, la aplicabilidad de los ODS queda más despejada puesto que se parte, desde el principio, de los diversos componentes que integran la noción de desarrollo. Como se ha dicho:

l'adoption d'un cadre post-2015 audacieux et large ne garantit pas que les pays réussiront à s'attaquer aux quatre dimensions du développement durable. Pourtant, il semble difficile d'imaginer que des progrès significatifs puissent être réalisés en termes d'éradication de la pauvreté, de promotion du développement économique, d'inclusion sociale et de promotion de la durabilité environnementale sans un cadre commun international. C'est pourquoi la réussite de l'adoption d'un ensemble d'objectifs audacieux et opérationnels est si importante ${ }^{59}$.

56 BoyLe, A., «Derecho internacional...», cit., p. 12.

57 La Resolución 70/1 sostiene que «estamos decididos a poner fin a la pobreza y el hambre en todas sus formas y dimensiones, y a velar por que todos los seres humanos puedan realizar su potencial con dignidad e igualdad y en un medio ambiente saludable».

58 Rodrigo HernándeZ, A. J., «El concepto de desarrollo sostenible...», cit., p. 200.

59 Lan, X.; Sachs, J. D.; Schmidt-Traub, G. y Tubiana, L., Définir des objectifs..., cit. 
Las dimensiones del desarrollo sostenible han sido afirmadas, de manera paulatina, y se han reflejado, como decimos, en numerosos instrumentos sobre la materia. En la actualidad, no sería posible entender el desarrollo sostenible, y menos extraer consecuencias prácticas de esta noción, sin tener en cuenta el crecimiento y el desarrollo económico; sin propiciar el desarrollo social poniendo al ser humano en el centro de las políticas de desarrollo ${ }^{60} ; \mathrm{y}$ sin establecer una indisoluble vinculación entre desarrollo y medio ambiente ${ }^{61}$.

Con ello, podemos apreciar, con nitidez, algunas de las consecuencias que se derivan de cada una de las dimensiones de las que se ha dotado al desarrollo sostenible tanto en su concepción teórica como en su contenido práctico. Dimensiones que, además, se pueden ir ampliando, como se sabe, en lo relativo a los aspectos institucionales y de seguridad del desarrollo y en el ámbito de los aspectos de carácter cultural ${ }^{62}$.

i) El desarrollo sostenible se sitúa en el marco apropiado para crear las condiciones que aseguren un esquema económico que permita el logro de los ODS. En el Programa de Desarrollo se señalaba que «si bien el fin de la guerra fría ha fomentado un nuevo espíritu de diálogo y cooperación a nivel político en el mundo entero, es necesario mejorar el entorno económico internacional de manera que sea más favorable al desarrollo socioeconómico de los países en desarrollo, especialmente mediante el cumplimiento de los compromisos

60 «Desde la Conferencia de las Naciones Unidas sobre el Medio Ambiente y el Desarrollo (Cumbre para la Tierra) celebrada en 1992 en Río de Janeiro (Brasil), hemos encontrado una nueva vía para lograr el bienestar humano: el camino del desarrollo sostenible. La Declaración del Milenio y los Objetivos de Desarrollo del Milenio establecidos en 2000 colocaron a las personas en el centro del desarrollo y generaron mejoras sin precedentes en la vida de muchas personas en todo el mundo», El camino hacia la dignidad para 2030: acabar con la pobreza y transformar vidas protegiendo el planeta, Informe de sintesis del Secretario General sobre la agenda de desarrollo sostenible después de 2015, A/69/700, 4 de diciembre de 2014, párr. 9.

61 «a única forma de asegurar economías fuertes y erradicar la pobreza es mediante la protección del medio ambiente, al salvaguardar los ecosistemas que mantienen el bienestar humano y al mitigar el cambio climático y sus impactos», $A B C$ de los objetivos de desarrollo sostenible, cit., p. 14.

62 La dimensión institucional y de seguridad ha quedado reflejada en el Objetivo 16 de los ODS. Este Objetivo pretende «promover sociedades pacíficas e inclusivas para el desarrollo sostenible, facilitar el acceso a la justicia para todos y construir a todos los niveles instituciones eficaces e inclusivas que rindan cuentas». Por lo demás, existen muy pocas referencias en la Resolución 70/1 a la dimensión cultural. Tan sólo algunas indicaciones, muy marginales, a la diversidad cultural. GUEVREMONT, V., «La reconnaissance du pilier culturel du dévéloppement durable: vers un nouveau mode de diffusion des valeurs culturelles au sein de l'ordre juridique mondial», A.C.D.I. (2012), pp. 163-195; y Nishiumi, M., «The cultural aspects of sustainable development», F.Y.I.L. (2014), pp. 305-332. 
convenidos en las conferencias importantes de las Naciones Unidas celebradas recientemente ${ }^{63}$. El desarrollo sostenible tiene, con toda seguridad, un contenido de carácter económico y su ejercicio y efectividad dependen, también, de las circunstancias económicas. La Declaración con motivo del Cincuentenario de las Naciones Unidas, en el primer párrafo de los dedicados al desarrollo, señaló que «un entorno económico internacional dinámico, vigoroso, libre y equitativo es indispensable para el bienestar de la humanidad y para la paz, la seguridad y la estabilidad internacionales».

Desde el principio, la vinculación entre crecimiento económico y desarrollo ha sido una constante en la escena internacional y los diferentes instrumentos que se ocupan del desarrollo no han dejado de señalar, con trazo grueso, esta relación. Los ODS apuntan, con reiteración, en esta dirección. La Resolución 70/1, en el párrafo 3, indica que «estamos resueltos también a crear las condiciones necesarias para un crecimiento económico sostenible, inclusivo y sostenido, una prosperidad compartida y el trabajo decente para todos, teniendo en cuenta los diferentes niveles nacionales de desarrollo y capacidad».

El desarrollo sostenible debe concebirse en el marco del Derecho Internacional Económico. Por esto, según V. Abellán Honrubia, «una de las propuestas más sugestivas y audaces para la promoción del desarrollo de los países en vías de desarrollo llevada a cabo por las N.U., es (fue) la contemplada en la Declaración sobre el establecimiento de un Nuevo Orden Económico Internacional» ${ }^{64}$. Se trata de poner el énfasis en que el establecimiento de normas en materia de derecho internacional económico debe suponer la inclusión de la normativa referente al desarrollo. En la actual sociedad internacional, las cuestiones relativas al desarrollo no presentan un carácter marginal sino que, por el contrario, ocupan un lugar central en los procesos de creación de

63 Programa de Desarrollo, A/RES/51/240, 15 de octubre de 1997, párr. 24.

64 Abellan Honrubia, V., «El Derecho Internacional Económico», en M. Díez De Velasco, Instituciones de Derecho Internacional Público, Madrid, 1999, p. 586. Para esta autora el «Derecho Internacional del Desarrollo» constituye uno de los ámbitos materiales del «Derecho Internacional Económico», p. 582. Además, «la consideración del desarrollo desde la perspectiva internacional, ha propiciado que su noción no se circunscriba únicamente a los problemas que se suscitan en el interior de cada Estado, sino que debe elaborarse teniendo en cuenta las circunstancias y condicionamientos tanto económicos como políticos existentes en las relaciones entre los Estados. Por ello, la noción de desarrollo en el ámbito del derecho internacional ha ido vinculada normalmente a las exigencias del sistema económico imperante en la sociedad internacional (...) a su percepción en cada momento, y a las distintas coyunturas de la política internacional», p. 583 . 
normas en el ámbito económico. El Derecho Internacional Económico tiene como una de sus partes centrales el derecho al desarrollo. Por esto, «si un nouvel ordre doit se metre progessivement en place dans le domaine économique, il devra se construire en associant étroitement les principes du droit international du développement: le sous-développement reste l'un des problèmes majeurs de l'économie mondiale» ${ }^{65}$.

La comunidad internacional, con mayor o menor éxito, ha puesto en marcha numerosas estrategias destinadas a garantizar el crecimiento y el desarrollo económico. El logro de los ODS no sería posible fuera de un marco económico que permita el crecimiento y que favorezca los componentes de desarrollo. El punto 13 de la Resolución 70/1 se expresa con toda nitidez en esta línea. La expresión «crecimiento económico sostenido» se repite hasta la saciedad en la Agenda 2030 y se constituye en uno de los fundamentos para el logro de los ODS.

$\mathrm{El}$ ¿fracaso? del N.O.E.I. y la difícil aceptación, por la comunidad internacional, de las normas en materia de desarrollo, no impide que el conjunto de normas que diseñe el Derecho Internacional Económico tengan en cuenta el objetivo de desarrollo sostenible. La propia Resolución sobre el Derecho al Desarrollo establece esta vinculación entre orden económico y derecho al desarrollo en el párrafo 3, del artículo 3, cuando dispone que «los Estados deben realizar sus derechos de modo que promuevan un nuevo orden económico internacional basado en la igualdad soberana, la interdependencia, el interés común y la cooperación entre todos los Estados, y que fomenten la observancia y el disfrute de los derechos humanos». Relación que, sin duda, aporta viabilidad a la consecución de los ODS. La cooperación en el ámbito económico es, por lo tanto, una condición necesaria para que se alcancen estos objetivos y, en verdad, los Estados han asumido el compromiso de conducir su comportamiento en el marco del crecimiento económico sostenido.

El Derecho Internacional económico no tendría, por lo tanto, como únicas metas regular las relaciones económicas entre los Estados y otros entes que intervienen en las relaciones internacionales, sin tener en cuenta objetivos tales como la promoción y defensa de los países en desarrollo. Resulta innegable que este sector del ordenamiento jurídico internacional ha evolucionado,

65 RoBert, E., «Le nouvel ordre mondial à l'épreuve du désordre économique international», en P. Herman, Le monde selon Bush: genèses d'un nouvel ordre mondial, Association Droit des Gens, A la recherche du nouvel ordre mondial, t. I., 1993, pp. 239-240. 
de manera lenta, en un sentido más justo y más conforme con los intereses de los países más débiles ${ }^{66}$. Está también impregnado de la defensa de intereses comunes que van más allá de las posiciones concretas que adopten, en cada caso, los Estados y las Organizaciones internacionales en la defensa de sus posiciones particulares.

La dimensión económica del desarrollo sostenible es fundamental para poder afirmar el significado de esta noción en el orden internacional y, sobre todo, para extraer consecuencias y efectos jurídicos de las pautas y guías de comportamiento que se fijan en los ODS. Sin crecimiento económico no es posible alcanzar estos objetivos por más que dicho crecimiento deba ser, necesariamente, sostenido. Sólo se puede lograr el desarrollo sostenible mediante el crecimiento económico. Las relaciones económicas, en la escena internacional, se proyectan ahora sobre un marco mucho más general y como una dimensión sobresaliente para el logro de los ODS.

ii) El desarrollo sostenible tiene, también, una dimensión social. Todos los instrumentos que se han adoptado en esta materia resaltan esta dimensión y ponen el acento en las implicaciones que, en lo social, tiene el desarrollo. En efecto, «el desarrollo económico, basado tan sólo en el incremento de la tasa de crecimiento y en la transferencia de recursos financieros en favor de los países en vías de desarrollo, no era suficiente si no implicaba también la justicia social en forma de reducción de la pobreza, el analfabetismo y las enfermedades o de la igualdad entre hombre y mujer; es decir, si no proporcionaba ventajas materiales y morales a las personas ${ }^{67}$. Se abre, por lo tanto, una nueva dimensión en materia de desarrollo que se puede conceptuar como la búsqueda del desarrollo social ${ }^{68}$.

${ }^{66}$ Cfr. Horchani, F., «Le nouvel ordre économique international: mort ou métamorphose?», en R. B. Achoir y S. Laghmani (dirs.), Les nouveaux aspects du droit international, París, 1994, p. 209. Para este autor, el derecho, y menos aún el derecho internacional, no es neutro, por lo que se puede decir que el derecho internacional económico, que descansa en una filosofía económica liberal, ha sido capaz de adaptarse a las más grandes y profundas transformaciones que están ocurriendo en la sociedad internacional, cfr., p. 200.

67 Para este autor, «en la actualidad, el desarrollo social es uno de los componentes imprescindibles para el desarrollo sostenible y uno de los objetivos políticos de primera magnitud que se han incorporado a la agenda internacional en los últimos años del siglo pasado, en particular, a partir de la Cumbre mundial sobre desarrollo social celebrada en Copenhague los días 11 y 12 de marzo de 1995», RODRIGO HERNÁNDEZ, A. J., «El concepto de desarrollo sostenible...», cit., pp. 178 y 180.

68 FLORY, M., loc. cit., pp. 631-632. 
La erradicación de la pobreza se ha constituido en el principal objetivo de los Objetivos de Desarrollo. La Declaración del Mileno, en 2000, en su punto 11 , establecía que «no escatimaremos esfuerzos para liberar a nuestros semejantes, hombres, mujeres y niños, de las condiciones abyectas y deshumanizadoras de la pobreza extrema, a la que en la actualidad están sometidos más de 1.000 millones de seres humanos. Estamos empeñados en hacer realidad para todos ellos el derecho al desarrollo y a poner a toda la especie humana al abrigo de la necesidad». El primero de los ODM va ser, precisamente, «erradicar la pobreza extrema y el hambre. Esta es la más sólida y amplia consideración social». Los ODS también ponen el acento en esta cuestión. En el punto 2 de la Resolución 70/1 se indica que «la erradicación de la pobreza en todas sus formas y dimensiones, incluida la pobreza extrema, es el mayor desafío a que se enfrenta el mundo y constituye un requisito indispensable para el desarrollo sostenible». El primero de los ODS es, en particular, «poner fin a la pobreza en todas sus formas y en todo el mundo». La importancia de lo social queda, entonces, garantizada en la Agenda 2030.

El desarrollo no se vincula sólo al crecimiento económico y a las inversiones y flujos financieros sino que, paulatinamente, ha ido adquiriendo un carácter social. Incluso, el desarrollo ha ido más allá de la mera protección del medio ambiente. Se dice que «el desarrollo sustentable implica no solo limitar la actividad económica para preservar y proteger el medio ambiente, sino abordar el desarrollo con un enfoque que enfatiza la importancia fundamental de la equidad dentro del sistema económico. Esta equidad es a la vez intrageneracional, en el sentido de que persigue corregir el desequilibrio en materia de riqueza y desarrollo económico entre el mundo desarrollado y el mundo en desarrollo dándole prioridad a las necesidades de los pobres, como intergeneracional, en el sentido de que busca una justa distribución de costos y beneficios a través de las generaciones» ${ }^{69}$.

La dimensión social del desarrollo tiene, sin embargo, dos vertientes complementarias: Por un lado, lo social en materia de desarrollo conlleva la afirmación del desarrollo bumano. El ser humano, gracias a la introducción de una «nueva dimensión ética en la consideración de las relaciones económicas internacionales» ${ }^{70}$, comienza a ser el destinatario de normas internacionales en materia no sólo de protección de los derechos humanos en sentido estricto, sino,

69 BOYLE, A., Derecho internacional y desarrollo sustentable, cit., p. 7.

70 Abellan Honrubia, V., Algunas consideraciones sobre el Nuevo Orden, cit., p. 220. 
también, de conservación y mejora del medio ambiente, y del crecimiento y desarrollo económicos. Con ello, se establece una clara vinculación entre desarrollo y protección de los derechos humanos que va a tener consecuencias no sólo políticas sino también, de naturaleza jurídica.

El surgimiento y formación de nuevos derechos y el fortalecimiento de derechos de contenido social, ya reconocidos, serán las principales consecuencias de esa vinculación. En la Resolución 70/1 se reconoce que «la dignidad de la persona humana es fundamental»y, al mismo tiempo, la nueva agenda se fundamenta en «la Declaración Universal de Derechos Humanos, los tratados internacionales de derechos humanos». En concreto el punto 19 de la Declaración, de 2015, sostiene que «reafirmamos la importancia de la Declaración Universal de Derechos Humanos, así como de otros instrumentos internacionales relativos a los derechos humanos y el derecho internacional. Ponemos de relieve que, de conformidad con la Carta de las Naciones Unidas, todos los Estados tienen la responsabilidad de respetar, proteger y promover los derechos humanos y las libertades fundamentales de todas las personas, sin hacer distinción alguna por motivos de raza, color, sexo, idioma, religión, opinión política o de cualquier otra índole, origen nacional o social, posición económica, nacimiento, discapacidad o cualquier otra condición».

Todo ello, sin entrar, además, en la consideración del desarrollo como derecho humano y las implicaciones teóricas y prácticas que tiene una afirmación de este tipo. En realidad «el desarrollo se entiende como derecho bumano, caracterizado por ser multidimensional en sus objetivos y componentes, tener diferentes titulares (en la medida que el desarrollo se predica de personas y de colectivos), por ser de realización progresiva (proceso de mejoramiento y satisfacción de necesidades siempre perfectible) y de implementación tanto en la esfera nacional como la internacional $\gg^{71}$.

Por otro lado, la dimensión social del desarrollo nos lleva a considerar múltiples aspectos que están presentes en las finalidades que persigue el desarrollo sostenible. La formulación de los ODS descansa, principalmente, en el logro de objetivos de contenido social. Buena parte de los 17 ODS se dirigen a cubrir necesidades de carácter social y, en algunos casos, los objetivos económicos y medio ambientales en sentido estricto se formulan en términos sociales.

71 Institut Català Internacional Per la PAU, Escenarios posconflicto en Colombia, Agenda, oportunidades y hoja de ruta. Relatoría del seminario, Barcelona, 5, 6 y 7 de mayo de 2014, p. 23. 
A pesar de que la expresión «desarrollo social» no se haya empleado mucho en la Resolución 70/1, la mera lectura de la Declaración y los objetivos y metas de la nueva agenda 2030 expresan, con toda transparenciaa, la relevancia que se otorga a los contenidos sociales.

Diversos aspectos de los ODS tienen un significado social y, en verdad, se cubren las principales áreas en las que deben lograrse objetivos sociales. La educación, la salud, la vivienda y el empleo, como más significativos, están presentes en la noción de desarrollo sostenible. Aparecen bien de manera autónoma en algunos de los ODS o bien se insertan, con naturalidad, en el marco de algunos de los ODS de contenido social que se formulan con mayor amplitud. En el fondo, la dimensión social de los ODS está presente y reafirma el contenido social de la noción de desarrollo sostenible hasta el punto de que no sería posible concebir esta noción y las consecuencias políticas y jurídicas que se derivan sin tener muy en cuenta los componentes sociales del desarrollo.

iii) No sería posible comprender el desarrollo sostenible si se prescinde de la dimensión ambiental. Sin duda, «la protección del medio ambiente es uno de principales objetivos de la Comunidad internacional y un componente esencial del desarrollo sostenible ${ }^{72}$. Precisamente el desarrollo ha llegado a entenderse como desarrollo sostenible por la incorporación plena de las cuestiones relativas a la protección internacional del medio ambiente. El punto 3 de la Declaración de 2015 expresa el compromiso de «garantizar una protección duradera del planeta y sus recursos naturales». El conjunto de la Resolución 70/1 está impregnado de referencias en las que se destaca la dimensión medioambiental del desarrollo. En el punto 7 de la Declaración se aspira, en particular, a «un mundo en el que reafirmemos nuestros compromisos sobre el derecho humano al agua potable y al saneamiento, donde haya mejor higiene y los alimentos sean suficientes, inocuos, asequibles y nutritivos; un mundo cuyos hábitats humanos sean seguros, resilientes y sostenibles y donde haya acceso universal a un suministro de energía asequible, fiable y sostenible». Los ODS, además del contenido social, inciden en la cuestión medioambiental. Buena parte de estos objetivos se destinan a cuestiones de esta índole. En particular, «combatir el cambio climático; conservar y utilizar sosteniblemente los océanos, los mares y los recursos

72 Rodrigo Hernández, A. J., «El concepto de desarrollo sostenible...», cit., pp. 183-184. 
marinos; y proteger, restablecer y promover el uso sostenible de los ecosistemas terrestres, gestionar sosteniblemente los bosques, luchar contra la desertificación, detener e invertir la degradación de las tierras y detener la pérdida de biodiversidad».

La incorporación del medio ambiente a la noción de desarrollo ha sido progresiva y se ha plasmado en numerosos instrumentos internacionales. Era necesario que el crecimiento económico viniese acompañado de la cuestión medioambiental. En el punto 33 de la Declaración, de 2015, se afirma que el «desarrollo social y económico depende de la gestión sostenible de los recursos naturales de nuestro planeta. Por ello, estamos decididos a preservar y utilizar sosteniblemente los océanos y los mares, los recursos de agua dulce y los bosques, las montañas y las zonas áridas, y a proteger la diversidad biológica, los ecosistemas y la flora y fauna silvestres». Se instauró, así, una vinculación muy estrecha entre el desarrollo económico y el medio ambiente a pesar de pertenecer a dos sectores distintos del orden internacional.

Es, sobre todo, a partir de 1992 cuando se produce esta vinculación y surge, con intensidad, el concepto de desarrollo sostenible. En efecto, «la integración de la protección del medio ambiente y el desarrollo económico era un objetivo importante de la Conferencia de las Naciones Unidas sobre el Medio Ambiente y el Desarrollo, expresado en el Principio 4 de la Declaración de Río» ${ }^{73}$. A partir de entonces, sólo se puede abordar la noción de desarrollo sostenible sobre la base de la consideración, muy particular, del componente correspondiente al medioambiente.

La incorporación progresiva de diferentes dimensiones a la noción de desarrollo sostenible refuerza, con toda seguridad, este concepto y promueve que pueda adquirir la categoría de principio del que vayan emanando obligaciones. No obstante, es posible que la noción pierda algunos aspectos de su autonomía conceptual y normativa y que quede condicionada por los componentes, con los derechos y obligaciones que derivan de esas dimensiones. En otras palabras, si bien las dimensiones de la noción de desarrollo sostenible enriquecen la plasmación de un principio político-jurídico al respecto y, por ende, el cumplimiento de los ODS, sin embargo, se suscita la cuestión de si la proliferación de dimensiones no debilita, en algún modo, la formulación del desarrollo sostenible como un principio estructural del orden internacional.

73 Boyle, A., Derecho internacional y desarrollo sustentable, cit., p. 7. 


\section{CONCLUSIONES}

La formulación de los ODS responde a la voluntad de los Estados de crear un mundo mejor y poner fin a la pobreza y a las desigualdades en la sociedad internacional. La nueva Agenda 2030 es un plan muy ambicioso que señala principios y pautas de comportamiento para los Estados y que implica, también, al conjunto de los actores que intervienen en la sociedad internacional contemporánea. Pero el marco en el que se deben ejecutar estos objetivos debe incorporar componentes de carácter jurídico y no sólo elementos de naturaleza política. No se trata de buscar tan sólo formulaciones meramente políticas cuyo incumplimiento no entrañe ningún tipo de responsabilidad internacional. El modo en que los Estados han proclamado los ODS hace referencia tanto al principio que sustenta el desarrollo como a las principales dimensiones a través de las cuales se manifiesta en la actualidad este noción. Es difícil precisar la noción de desarrollo sostenible y su significado resulta complicado reducirlo a términos jurídicos. Por lo menos, «a pesar de que es posible identificar los componentes principales del concepto, dista mucho de saberse cuáles son sus consecuencias normativas específicas, o incluso cómo se relacionan entre sí o con el derecho de los derechos humanos y el derecho internacional económico» ${ }^{74}$.

La única forma de reconocer la eficacia de los ODS será precisando, cada vez más, el contenido de la noción de desarrollo sostenible y vinculándola a algunos de los principios esenciales del orden internacional. De esta noción emanan principios, normas, guías y pautas de comportamiento y se combinan, a veces con dificultades para distinguir, compromisos políticos y algunas obligaciones de comportamiento con significación jurídica. En todo caso, la noción ha contribuido a fortalecer algunos sectores del ordenamiento jurídico internacional. En particular, «el vigoroso compromiso de la comunidad internacional con el concepto de desarrollo sustentable ha tenido un apreciable impacto en la evolución del derecho internacional ambiental existente y en el desarrollo del nuevo derecho» ${ }^{75}$. No se deben ocultar, por lo tanto, los efectos que la Nueva Agenda 2030 puede producir en el orden internacional y, por lo menos, el modo en el que refuerza el principio de desarrollo sostenible, como un principio autónomo de este orden.

74 Ibid., p. 17.

75 Ibid., p. 15. 
Los ODS son el último escalón que debe conducir al desarrollo sostenible a su afirmación y consagración como principio estructural del derecho internacional del tiempo presente y sería conveniente que los Estados comenzasen a extraer consecuencias del ingente número de compromisos que se contienen en la Nueva Agenda 2030. Por ello, los ODS no se deben entender como un mero plan de acción de carácter programático sino, también, como un instrumento capaz de forzar a los Estados que integran la comunidad internacional a asumir sus obligaciones en los campos cubiertos por el desarrollo sostenible. La aceptación de los ODS ha sido universal, como universal fue la aprobación y el proceso de ejecución de los ODM. Este carácter universal debe conducir a la formación de un principio estructural reconocido por los Estados, por la doctrina científica y por la jurisprudencia internacional. Nada impide, en la actualidad, que el desarrollo sostenible pase a formar parte de los principios que estructuran el orden internacional y de los que derivan las principales normas que regulan la convivencia en la comunidad internacional.

La existencia de diversas dimensiones en la noción de desarrollo sostenible no debe confundir a la hora de especificar las obligaciones que derivan de una noción de este tipo. Tampoco debe hacer más compleja y abigarrada dicha noción. La combinación de esas dimensiones debe favorecer el surgimiento de obligaciones precisas en aquellos campos que no están cubiertos por ningún otro de los principios esenciales del orden internacional. Al mismo tiempo, estas dimensiones cumplen la función de reforzar la protección de los derechos reconocidos y, también, incidir en aquellas materias que precisan una mayor aceptación por parte de la comunidad internacional. La dimensión económica señala un marco de actuación en el que la integración económica ${ }^{76}$ de los Estados se configura como un factor fundamental para alcanzar el crecimiento y desarrollo económicos. Todo ello, sin descuidar que ha de tratarse de un desarrollo económico sostenido. La dimensión social perfila derechos de contenido social y los fortalece en los sistemas universales y regionales de protección de los derechos humanos y, al mismo tiempo, lanza un reto de grandes dimensiones para la comunidad internacional al asumir el compromiso político de erradicar el

76 El párrafo 21 de la Resolución 70/1 destaca «la importancia que para el desarrollo sostenible tienen las dimensiones regionales y subregionales, la integración económica regional y la interconectividad. Los marcos regionales y subregionales pueden hacer que sea más fácil traducir efectivamente las políticas de desarrollo sostenible en medidas concretas a nivel nacional». 
hambre y la pobreza del planeta ${ }^{77}$. La dimensión ambiental refuerza, también, el papel del principio de la protección internacional del medio ambiento en el orden internacional y perfila los sectores más relevantes en los que debe incidir la comunidad internacional en la protección de los ecosistemas. Esta dimensión es fundamental para entender la noción de desarrollo sostenible ${ }^{78}$.

La Declaración de 2015, como último paso hasta ahora del desarrollo sostenible, supone la rebelión de aquellos principios que no han logrado alcanzar la categoría de principios estructurales del orden internacional y, asimismo, la beligerancia de aquellos otros principios que no quieren permanecer en el ámbito de las obligaciones «vaporosas». El principio del desarrollo y el principio de la protección internacional del medioambiente aspiran a conformarse como principios estructurales del orden internacional de los que deriven normas precisas y que impongan obligaciones para los Estados y otros actores de las relaciones internacionales y que otorguen derechos. En definitiva, que la formulación de algunos de los compromisos asumidos por estos principios entrañen responsabilidad internacional.

Los principios de la protección de los derechos humanos y de la cooperación internacional, reconocidos y consolidados en el orden internacional, pretenden llenarse de contenido desde que fueron proclamados como principios fundamentales. Por una parte, los derechos de contenido social precisan, ciertamente, de un impulso decidido de la comunidad internacional y de la instauración de mecanismos que aseguren su cumplimiento. Por otra parte, la cooperación debe expresarse no sólo en una obligación genérica sino a través de obligaciones precisas de cooperar para el logro del desarrollo sostenible. En esto tendrán una importancia capital los principios sectoriales que derivan de la noción de desarrollo sostenible.

77 El párrafo 24 de la Resolución 70/1 subraya el compromiso de «poner fin a la pobreza en todas sus formas y dimensiones, lo que incluirá erradicar la pobreza extrema de aquí a 2030. Todas las personas deben disfrutar de un nivel de vida básico, incluso mediante sistemas de protección social. También estamos decididos a poner fin al hambre y lograr la seguridad alimentaria como prioridad, y a eliminar todas las formas de malnutrición».

78 El párrafo 33 de la Resolución 70/1 sostiene que «el desarrollo social y económico depende de la gestión sostenible de los recursos naturales de nuestro planeta». Y expresa la determinación de «preservar y utilizar sosteniblemente los océanos y los mares, los recursos de agua dulce y los bosques, las montañas y las zonas áridas, y a proteger la diversidad biológica, los ecosistemas y la flora y fauna silvestres. También estamos decididos a promover el turismo sostenible, hacer frente a la escasez de agua y su contaminación, fortalecer la cooperación sobre la desertificación, las tormentas de arena, la degradación del suelo y la sequía y promover la resiliencia y la reducción del riesgo de desastres». 
La realidad se impone. La Agenda 2030 supone el reconocimiento de compromisos políticos, la definición de guías de conducta, el establecimiento de pautas de comportamiento y la aceptación por lograr el desarrollo sostenible en todas sus manifestaciones. Pero, al final, corresponderá a los Estados el cumplimiento de todas estas indicaciones. En verdad,

the primary enforcers of international norms remain the states themselves, and although sustainable development may be used by judges, it is not addressed to them. It is addressed to legal subjects, i.e., states. States are under an obligation to pursue sustainable development; they are bound by an obligation of means, and by implementing these countless treaties they contribute, day after day, to progressively making sustainable development requirements real ${ }^{79}$.

79 Barral, V., Sustainable Development..., cit., p. 398. 